\title{
A Biopolymer Chitosan and Its Derivatives as Promising Antimicrobial Agents against Plant Pathogens and Their Applications in Crop Protection
}

\author{
Mohamed E. I. Badawy ${ }^{1}$ and Entsar I. Rabea ${ }^{2}$ \\ ${ }^{1}$ Department of Pesticide Chemistry and Technology, Faculty of Agriculture, Alexandria University, El-Shatby, Alexandria 21545, Egypt \\ ${ }^{2}$ Department of Pest Control and Environmental Protection, Faculty of Agriculture, Damanhour University, Damanhour 22516, Egypt
}

Correspondence should be addressed to Mohamed E. I. Badawy, m_eltaher@yahoo.com

Received 22 January 2011; Revised 8 March 2011; Accepted 22 March 2011

Academic Editor: Bruno Sarmento

Copyright ( 92011 M. E. I. Badawy and E. I. Rabea. This is an open access article distributed under the Creative Commons Attribution License, which permits unrestricted use, distribution, and reproduction in any medium, provided the original work is properly cited.

Recently, much attention has been paid to chitosan as a potential polysaccharide resource. Although several efforts have been reported to prepare functional derivatives of chitosan by chemical modifications, few attained their antimicrobial activity against plant pathogens. The present paper aims to present an overview of the antimicrobial effects, mechanisms, and applications of a biopolymer chitosan and its derivatives in crop protection. In addition, this paper takes a closer look at the physiochemical properties and chemical modifications of chitosan molecule. The recent growth in this field and the latest research papers published will be introduced and discussed.

\section{Introduction}

Plant pathogens are considered economically important agricultural micro-organisms around the world. They induce decay on a large number of agricultural crops during the growing season and postharvest. Chemical pesticides provide the primary means for controlling the plant pathogens. However, continuous use of such compounds has faced two major obstacles: increasing public concern regarding contamination of perishable agricultural products with pesticide residues and proliferation of resistance in pest populations [1-3]. Hence, there is growing emphasis on environmentally friendly technologies in pest control, and evaluation of various alternatives to reduce dependency on harmful synthetic pesticides [4-6]. Consequently, several nonchemical treatments have been proposed for pest control. Although these approaches have been shown to reduce pests, each has limitations that can affect their commercial applicability. When used as stand-alone treatments, none of the nonchemical control methods has been clearly shown to offer a consistently economic level of disease control that warrants acceptance as an alternative to synthetic pesticides.
Among these strategies, some satisfactory results have been reported using natural compounds such as chitosan as safe alternative to hazardous pesticides with negligible risk to human health and the environment [7]. Chitosan, as the most abundant naturally occurring amino-polysaccharide, possesses many of these attributes and has attracted attention because of its unique physiochemical characteristics and biological activities $[6,8,9]$. From a biological standpoint, chitosan and its derivatives are very attractive for agriculture applications, which are closely related to human safety and fitness. For example, these compounds can function as seed soaking, root applying, and spray agents; all of these play an important role on plant disease control and stress resistance $[6,10]$.

The origin of chitosan (pronounced Kite-O-San) can be traced back to 1811 when "chitin", from which it is derived, was first discovered by Henri Braconnot, a professor of the natural history in France. According to some researches, while Braconnot was conducting research on mushrooms, he isolated what was later to be called chitin $[11,12]$. Chitin was the first polysaccharide identified by man, preceding cellulose by about 30 years. In the 1830s, there was a man 
who authored an article on insects in which he noted that similar substance was present in the structure of insects as well as the structure of plants. He then called this amazing substance as "chitin". Basically, the name chitin is derived from Greek, meaning "tunic" or "envelope". The concept was further known in 1843 when Lassaigne demonstrated the presence of nitrogen in chitin. In 1859, Professor C. Rouget subjected chitin to alkali treatment, which resulted in a substance that could, unlike chitin itself, be dissolved in acids. The term "chitosan" was given to deacetylated chitin by Hoppe-Seiler [13]. While chitin remained an unused natural resource for a long time, interest in this polymer and its derivatives such as chitosan and chitooligosaccharides has increased in recent years due to their unique properties. Intense interest applications grew in the 1930s; however, the lack of adequate manufacturing facilities and competition from synthetic polymers hampered the commercial development in this period. Renewed interest in the 1970s was encouraged by the need to better utilize shellfish shells and the scientists worldwide began to chronicle the more distinct properties of chitin and chitosan to understand the potential of these natural polymers. In the early 1960s, chitosan was investigated for its ability to bind with the red blood cells. That time also, it was considered as a hemostatic agent. Then, for the past three decades, chitosan has been used in water purification. Since then, numerous research studies have been undertaken to find ways to use these materials. Today, it is known as a dietary supplement that is good for weight loss. In fact, it has been marketed for such purpose for about 20 years in Japan as well as in Europe. Many people even call it as the "fat blocker" [14-18].

Chitosan is a linear aminopolysaccharide of glucosamine and $N$-acetylglucosamine units and is obtained by alkaline deacetylation of chitin extracted from the exoskeleton of crustaceans such as shrimps and crabs, as well from the cell walls of some fungi [19]. The following major characteristics of chitosan make this polymer advantageous for numerous applications: (1) it has a defined chemical structure; (2) it can be chemically and enzymatically modified; (3) it is physically and biologically functional; (4) it is biodegradable and biocompatible with many organs, tissues, and cells; (5) it can be processed into several products including flakes, fine powders, beads, membranes, sponges, cottons, fibers, and gels. Consequently, chitosan has found considerable application in various industrial areas [6, 20-22].

Owing to its high biodegradability, nontoxicity, and antimicrobial properties, chitosan is widely-used as an antimicrobial agent either alone or blended with other natural polymers. To broaden chitosan's antimicrobial applicability, comprehensive knowledge of its activity is necessary. The paper reviews the current trend of investigation on antimicrobial activities of chitosan and its derivatives against plant pathogens. The antimicrobial activity depends on several factors such as molecular weight, degree of deacetylation, solubility, positive charge density, chemical modification, $\mathrm{pH}$, concentration, hydrophilic/hydrophobic characteristic, chelating capacity, and type of microorganism. Mode of antimicrobial action is discussed in parts of the active compound and the target microorganisms collectively and independently in same complex. It has immense structural possibilities for chemical modifications to generate novel properties, functions, and applications especially in agricultural area. Therefore, different physiochemical properties and chemical modifications of chitosan molecule are also comparatively discussed. Finally, the general antimicrobial applications of chitosan and perspectives about future studies in this field are considered.

\section{Chitosan Structure and Natural Origin}

Chitin, occurring as a structural polysaccharide in the outer skeleton of animals belonging to the phylum Arthropoda (animals with an outer skeleton) and a component of the cell walls of certain fungi and algae, is quite abundant. It is also produced by a number of other living organisms in the lower plant and animal kingdoms, serving in many functions where reinforcement and strength are required. In contrast, chitosan is much less abundant in nature than chitin and has so far been found only in the cell walls of certain fungi [23]. Chitin is the raw material for all commercial production of chitosan and glucosamine, with estimated annual production of 2000 and 4000 tons, respectively [24]. Most commonly, chitin forms the skeletal structure of invertebrates. At least 10 Gtons $\left(1 \times 10^{13} \mathrm{Kg}\right)$ of chitin are constantly present in the biosphere [25]. Chitin is a linear polymer of $(1 \rightarrow 4)$-linked 2-acetamido-2-deoxy$\beta$-D-glucopyranose (GlcNAc; A-unit), which is insoluble in aqueous solvents. It also has many structural similarities with cellulose such as conformation of the monomers and diequatorial glycosidic linkages. Chitosan may be considered as a family of linear binary copolymers of $(1 \rightarrow 4)$-linked Aunits and 2-amino-2-deoxy- $\beta$-D-glucopyranose (GlcN; Dunit). The term chitosan does not refer to a uniquely defined compound; it merely refers to polysaccharides having different composition of $\mathrm{A}$ and $\mathrm{D}$ units, which is a white, hard, inelastic, and nitrogenous polysaccharide. It has been proposed to define chitin and chitosan based on their solubility in aqueous acetic acid, that is, chitosan as soluble and chitin as insoluble [26].

\section{Production of Chitosan}

A variety of procedures have been developed and proposed over the years for preparation of pure chitosan. Several of these form the basis of chemical processes for industrial production of chitosan from crustacean shell waste. For chitin production, the raw materials most abundantly available are the shells of crab, shrimp, and prawn (69$70 \%)[16,19,27]$. Because chitin is associated with other constituents, harsh treatments are required to remove them from chitinous material to prepare chitin and then chitosan on a large scale. Proteins are removed from ground shells by treating them with either sodium hydroxide or by digestion with proteolytic enzymes such as papain, pepsin, trypsin, and pronase [28]. Minerals such as calcium carbonate and calcium phosphate are extracted with hydrochloric acid. Pigments such as melanin and carotenoids are eliminated with $0.02 \%$ potassium permanganate at $60^{\circ} \mathrm{C}$ or hydrogen 
peroxide or sodium hypochlorite. Conversion of chitin to chitosan generally is achieved by hydrolysis of acetamide groups of chitin. This is normally conducted by severe alkaline hydrolysis treatment due to the resistance of such groups imposed by the trans-arrangement of the C2-C3 substituents in the sugar ring [29]. Thermal treatments of chitin under strong aqueous alkali are usually needed to give partially deacetylated chitin (degree of acetylation, DA $<30 \%$ ), regarded as chitosan. Usually, this process is achieved by treatment with concentrated sodium or potassium hydroxide solution $(40-50 \%)$ at $100^{\circ} \mathrm{C}$ or higher to remove some or all the acetyl groups from the polymer $[19,30,31]$. This process, called deacetylation, releases amine groups $\left(\mathrm{NH}_{2}\right)$ and gives the chitosan a cationic characteristic. This is especially interesting in an acid environment where the majority of polysaccharides are usually neutral or negatively charged. The deacetylation process is carried out either at room temperature (homogeneous deacetylation) or at elevated temperature (heterogeneous deacetylation), depending on the nature of the final product desired. However, the latter is preferred for industrial purposes. In some cases, the deacetylation reaction is carried out in the presence of thiophenol as a scavenger of oxygen or under $\mathrm{N}_{2}$ atmosphere to prevent chain degradation that invariably occurs due to peeling reaction under strong alkaline conditions [32]. One other method of preparing chitosan of improved purity is to dissolve the materials in an acid (e.g., acetic acid) and filter to remove extraneous materials. The clarified product is then lyophilized to give a water-soluble chitosonium acid salt or precipitated with $\mathrm{NaOH}$, washed, and dried to give a product in the free amine form [19].

Recent advances in fermentation technologies suggest that the cultivation of selected fungi can provide an alternative source of chitin and chitosan. The amount of these polysaccharides depends on the fungi species and culture conditions. Fungal mycelia are relatively consistent in composition and are not associated with inorganic materials; therefore, no demineralization treatment is required to recover fungal chitosan. Usually, the Zygomycetes class has higher amounts of chitin and chitosan in their cell walls when compared to other classes of fungi [33-42]. The use of biomass from fungi has demonstrated great advantages, such as: independence of seasonal factor, widescale production, simultaneous extraction of chitin and chitosan, extraction process is simple and cheap resulting in reduction in time and cost required for production, and also absence of proteins contamination, mainly the proteins that could cause allergy reactions in individuals with shellfish allergies [33, 43-47]. However, to optimize the production of chitin and chitosan from fungi, complex or synthetics cultures media, which are expensive are usually used. It has become necessary to obtain economic culture media that promote the growth of fungi and stimulate the production of the polymers. Recently, microbiological processes were used for chitin and chitosan production by Cunninghamella elegans grown by submerse fermentation in economic culture medium, yam bean (Pachyrhizus erosus L. Urban), as substrate [48]. The main characteristic of yam bean is the simple manipulation and low nutrition requirements when compared with other similar cultures, and tuberous roots yields are up to 60 ton/ha. The extraction of chitin and chitosan from different species of mushrooms (i.e., Agaricus bisporus, Auricularia auriculajudae, Lentinula edodes, Trametes versicolor, Armillaria mellea, Pleurotus ostreatus, Pleurotus sajor-caju, and Pleurotus eryngii) has been also illustrated $[39,49]$. The mushroom, P. sajor-caju, showed highest yield of biomass and L. edodes was the lowest when compared with others under submerged fermentation. The processes and conditions for the extraction of chitin and chitosan from mushroom were nearly same in the methods of Crestini et al. [50] and Pochanavanich and Suntornsuk [39], and were different in Mario et al. [49]. Moreover, the chitin composition and structure have been studied in insects, terrestrial crustaceans, and nematodes. However, their demineralization studies were carried out using $\mathrm{HCl}$ $(1-2 \mathrm{~N})$ for $0.3-96 \mathrm{~h}$ at $25-100^{\circ} \mathrm{C}$, which is stronger than the demineralization process of aquatic crustacean materials $[38,51-55]$.

\section{Physiochemical Properties of Chitosan}

4.1. Crystalline Structure. Since chitosan is a heterogeneous polymer consisting of GlcN and GlcNAc units, its properties depend on the structure and composition. Ogawa and Yui [56] studied the crystalline structure of different chitin/chitosan samples prepared by two different procedures: (a) the partial deacetylation of chitin, and (b) the partial reacetylation of a fully deacetylated chitin (pure chitosan). It was observed that the partially reacetylated material was less crystalline than pure chitosan. They also showed that, for the preparation of a less crystalline chitosan sample, it is preferable to proceed via reacetylation of fully deacetylated chitosan rather than direct solid-state deacetylation of chitin. This preferred treatment also resulted in less anhydrous crystals. Generally, the step of dissolving the polymer results in a decrease in the crystallinity of the material. However, it also depends on the secondary treatment (reprecipitation, drying, and freeze-drying). In addition, the origin may affect the residual crystallinity of chitosan, which in turn controls the accessibility to internal sorption sites and the diffusion properties (rehydration and solute transport) and also deacetylation procedure may affect the solid state structure of chitosan [57-59].

4.2. Degree of N-Acetylation. An important parameter to examine closely is the DA in chitin, that is, the ratio of GlcNAc to GlcN structural units. In chitin, the acetylated units prevail (DA $\geq 90 \%$ ), where as chitosan is fully or partially $N$ deacetylated derivative with a DA of less than $30 \%$. This ratio has a striking effect on chitin and chitosan solubility and solution properties. To define this ratio, attempts have been made with several analytical methods [18, 60-65], which include IR, UV, and NMR spectroscopies, pyrolysis gas, gel permeation chromatography (GPC), thermal analysis, various titration schemes, and acid hydrolysis. Furthermore, in case of chitin, the DA determines the suitable conditions of deacetylation, a complex process still requiring investigation in order to assess the feasibility of quicker preparation of 
chitosan. Thus, the search for quick, user-friendly, low cost, and accurate method to determine the DA has been one of the major concerns over many decades. However, the inherent complexity of this particular system turns this apparently simple analytical problem into a very difficult one, which is well illustrated by the extensive number of different techniques, either destructive or nondestructive, yielding direct or nondirect and frequently non reproducible values [26, 66-69]. It is worth noting that nondestructive methods offer the advantage of avoiding manipulations of the polymers such as hydrolysis, pyrolysis, or derivatization, the consequences of which are not always well known. Especially, FTIR spectroscopy is considered to be a very attractive technique, as it is nondestructive, fast, sensitive, user-friendly, low priced, and suitable for both soluble and nonsoluble samples [62]. Proton NMR spectroscopy is a convenient and accurate method for determining the chemical structure of chitosan and its derivatives [61, 70-73]. NMR measurements of chitosan compounds are, however, limited to samples that are soluble in the solvent, which limits the analysis of chitosan with DA values lower than 0.3 in aqueous solutions. A typical proton NMR spectrum of chitosan is shown in Figure 1. The signal at $\delta 3.20$ ppm was attributed to $\mathrm{H}-2$ of $\mathrm{GlcN}$ residue. The intense band at 4.8$5.30 \mathrm{ppm}$ is related to $\mathrm{OH}$ groups and $\mathrm{HDO}$ (solvent). In this region, as observed more clearly from an extended spectrum, some different anomeric protons (H-1 of GlcN and GlcNAc units) are appeared at $4.88-5.00 \mathrm{ppm}$. The DA is calculated from the integral ratio between protons of acetyl group and the GlcN protons. The degree of deacetylation (DDA) is calculated from the integral ratio between the proton on $\mathrm{C}$ 2 and the glucose unit protons $[71,74,75]$. The ${ }^{1} \mathrm{H}-\mathrm{NMR}$ spectra also allowed us to propose a method to determine the degree of substituent (DS) value and the determination is based on the ratio between the protons of the substituent and the protons of the pyranose unit [71, 76-79].

The role of the DA on the chain stiffness has essentially been assessed by viscometry considering the MarkHouwink-Kuhn-Sakurada (MHKS) relationship [80, 81], [ $\eta]$ $=K M^{a}$, and by static light scattering through the relation $R$ ${ }_{G}=K \mathrm{M}^{v}$, where $[\eta]$ and $R_{G}$ correspond to the intrinsic viscosity and the radius of gyration, respectively. Experiments have been performed either with parent samples having different degrees of polymerization [82] or with samples fractionated by size exclusion chromatography [83]. Many authors found an increase of the $a$ coefficient with DA and concluded that acetyl groups induce some stiffness to the chains $[82,84,85]$, whereas the dependence of $v$ on DA is less significant $[83,85,86]$.

4.3. Molecular Weight. As polysaccharides in general, chitosans are polydisperse with respect to molecular weight (MW). The MW difficulty encountered in this respect concerns the solubility of the samples and dissociation of aggregates often present in polysaccharide solution. As to choosing a solvent for chitosan characterization, various systems have been proposed, including an acid at a given concentration for protonation together with a salt to screen the electrostatic interaction because of the MW chitosan is an average over the whole distribution of Mws. The MW heterogeneity of polysaccharides can be described by several types of average MW. The two most common methods in use for averaging are the number-average, $\mathrm{Mn}$ (which weighs the polymer molecules according to the number of molecules having a specific MW) and the weight-average, Mw (which weighs the polymer molecules according to the weight of molecules having a specific MW). The MW of chitosan depends on its source and deacetylation conditions (time, temperature, and concentration of alkali). Chitosan obtained from deacetylation of crustacean chitin may have a MW over $100,000 \mathrm{Da}$. Consequently, it is necessary to reduce the MW by chemical or enzymatic methods to much lower MW for easy application and high biological activity.

In order to evaluate the MW of polymeric chain, various methods can be used extensively. Viscometric [87] and GPC [88] techniques are easy to perform and low time consuming. On the other hand, they are empirically related to the MW, because the measurement depends upon the hydrodynamic volume of the macromolecule, which is a function of the MW conformational properties, and polymer-solvent interaction. As a consequence, a calibration curve is required. The viscosity of chitosan solutions is measured by using Ubbelohde Viscometer. The running times of the solution and solvent are used to calculate the relative viscosity $\left(\eta_{\text {rel }}\right)$, specific viscosity $\left(\eta_{\mathrm{sp}}\right)$, and reduced viscosity $\left(\eta_{\text {red }}\right)$ as follows: $\eta_{\text {rel }}=t_{\mathrm{ch}} / t_{\mathrm{sol}} ; \eta_{\text {rel }}=t_{\mathrm{ch}} / t_{\mathrm{sol}} ; \eta_{\text {red }}=\eta_{\mathrm{sp}} / c$, where $t_{\mathrm{ch}}$ and $t_{\text {sol }}$ are the running times of the chitosan solution and solvent, respectively and $c$ is the chitosan concentration in $\mathrm{g} / \mathrm{dL}$. The intrinsic viscosity, defined as $[\eta]=\mathrm{C}\left(\eta_{\mathrm{red}}\right)_{\mathrm{c}=0}$, is obtained by extrapolating the $\eta_{\text {red }}$ versus concentration data to zero concentration and the intercept on the ordinate is the intrinsic viscosity $[82,89-91]$. Finaly the average molecular weight $(M)$ is calculated based on the MHKS equation $\left([\eta]=K M^{a}\right)$, where $K$ and $a$ are viscometric parameters depending on the solvent $[92,93]$. For example, a chitosan dissolved in $0.5 \mathrm{M} \mathrm{CH}_{3} \mathrm{COOH} / 0.2 \mathrm{M} \mathrm{CH}_{3} \mathrm{COONa}$, $K$ and $a$ were found to be $3.5 \times 10^{-4}$ ) and 0.76 , respectively according to Terbojevich et al. [94] and Wang et al. [82]. On the contrary, the light scattering (LS) method [95-97] gives absolute values for MW, but the technique is more difficult and sometimes the data are not easy to interpret.

4.4. Solubility and Charge Density. Chitin and chitosan degrade before melting, which are typical for polysaccharides with extensive hydrogen bonding. This makes it necessary to dissolve them in an appropriate solvent system to impart functionality. For each solvent system, polymer concentration, $\mathrm{pH}$, counter ion concentration, and temperature effects on the solution viscosity must be known. When the DDA of chitin reaches about 50\% (depending on the origin of the polymer), it becomes soluble in aqueous acidic media and is called chitosan. Comparative data from solvent to solvent are not available. As a rule, the maximum amount of polymer is dissolved in a given solvent towards a homogeneous solution. Subsequently, the polymer is regenerated in the required form. A coagulant is required for polymer regeneration or solidification. The nature of the coagulant is also highly dependent on the solvent and 


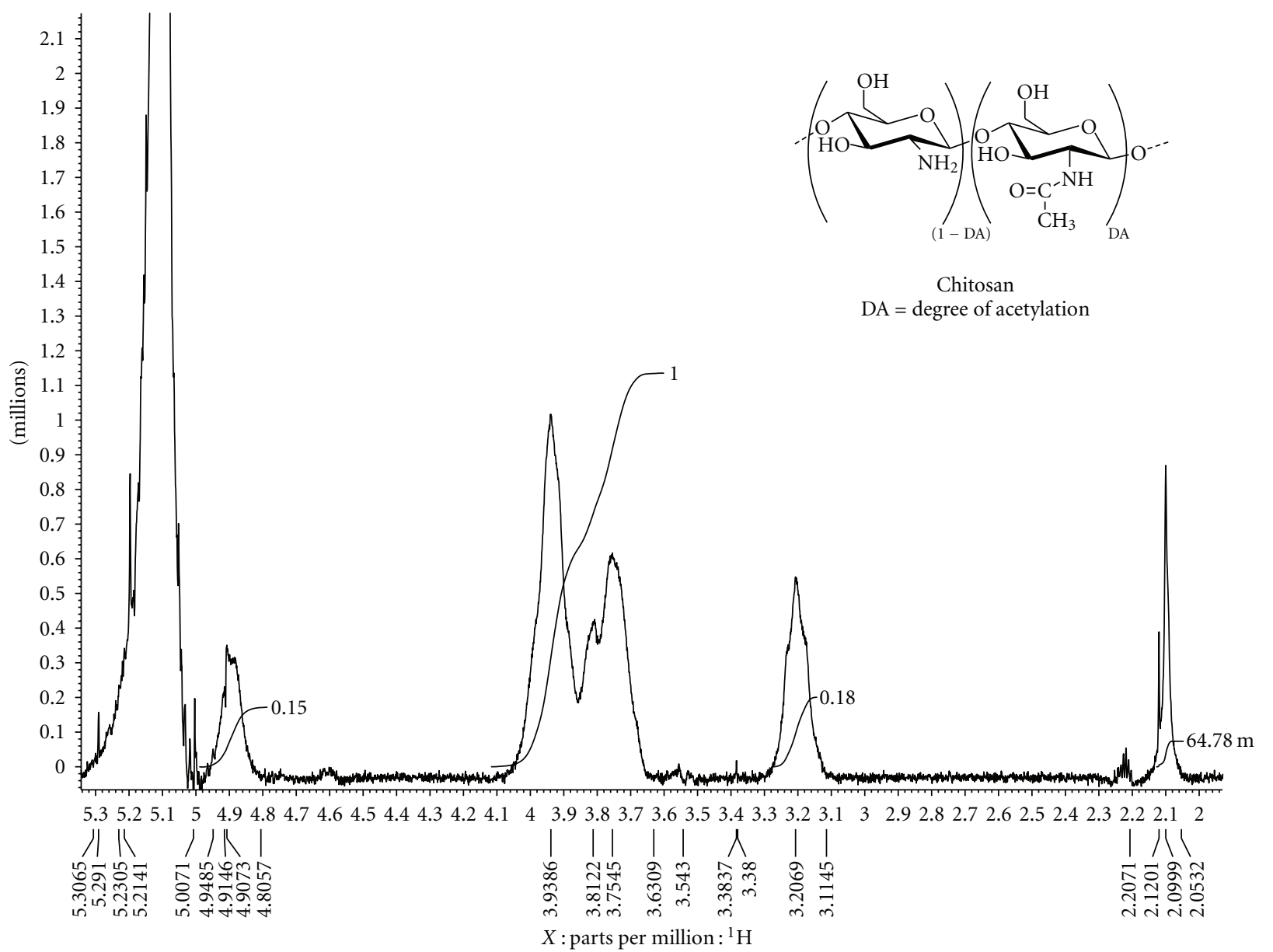

Figure $1:{ }^{1} \mathrm{H}-\mathrm{NMR}$ spectrum $(300 \mathrm{MHz})$ of chitosan in $0.5 \% \mathrm{CD}_{3} \mathrm{COOD} / \mathrm{D}_{2} \mathrm{O}$ at $25^{\circ} \mathrm{C}$.

solution properties as well as the polymer used [63, 98]. Chitosan, being a cationic polysaccharide in neutral or basic $\mathrm{pH}$ conditions, contains free amino groups on $\mathrm{C}-2$ of $\mathrm{GlcN}$ unit and hence, is insoluble in water. In acidic $\mathrm{pH}$, amino groups can undergo protonation thus, making it soluble in water. Therefore, solubility of chitosan depends upon the distribution of free amino and $N$-acetyl groups [99]. Usually $1-3 \%$ aqueous acetic acid solutions are used to solubilize chitosan [100]. The macromolecule chains are stretched caused by electrostatic repulsion of the $\mathrm{NH}_{3}^{+}$groups. The stretched chains will tend to be coiled with addition of salt because of the charge screening effect of added salt. The extent of solubility depends on the concentration and type of acid, where as the solubility decreases with increasing concentration of acid and aqueous solutions of some acids such as phosphoric, sulfuric, and citric acids are not good solvents [101]. The charge density of chitosan, that is, the degree of protonation of amino groups, is determined by the chemical composition, MW, and external variables such as $\mathrm{pH}$ and ionic strength. Dissociation constants $(p K a)$ for chitosan range from 6.2 to 7 , depending on the type of chitosan and conditions of measurement [61, 91, 102, 103]. A number of solvents for chitin and chitosan can be found in the literature. Generally, the solubility decreases with an increase in MW $[63,104]$. Moreover, few attempts have been made to enhance chitosan's solubility in organic solvents [105-108]. However, many other attempts have been made to enhance its solubility in water. One major reason is because most biological applications for chemical substances require the material to be processible and functional at neutral $\mathrm{pH}$. Thus, obtaining a water soluble derivative of chitosan is an important step towards the further application as a biofunctional material $[70,109,110]$.

4.5. Viscosity. Viscosity is an important factor in the conventional determination of chitosan MW and in determining its commercial applications. Higher MW chitosan often render highly viscous solutions, which may not be desirable for industrial handling. However, lower viscosity chitosans may facilitate easy handling. The solution viscosity of chitosan depends on its molecular size, cationic character, and concentration as well as the $\mathrm{pH}$ and ionic strength of the solvent [111]. The determination of the intrinsic viscosity of polyelectrolyte is an effective method to study the sensibility of polyelectrolyte to the addition of salt. Therefore, the dilute solution viscosity of three chitosan samples $(\mathrm{MW}=$ $2.6 \times 10^{5}, 5.6 \times 10^{5}$, and $\left.1.06 \times 10^{6} \mathrm{Da}\right)$ was measured both in solutions of $\mathrm{NaCl}$ with different ionic strengths 
$(0.01,0.03,0.06$, and $0.10 \mathrm{~mol} / \mathrm{L})$ and in those of $\mathrm{NaCl}, \mathrm{KCl}$, $\mathrm{CaCl}_{2}$, and $\mathrm{BaCl}_{2}$ with the same ionic strength $(0.06 \mathrm{~mol} / \mathrm{L})$, respectively [112]. It was found that the response of the intrinsic viscosity of chitosan to the added salts proceeds in the order of anion $\mathrm{Na}^{+}>\mathrm{K}^{+}>\mathrm{Ba}^{2+}>\mathrm{Ca}^{2+}$. According to the comparison of the ionic radius and hydrate number among the four anions, it is clear that the influence of intrinsic viscosity of chitosan on the added salt was due to both the anion radius and anion solvent power. Meanwhile the parameter of the MHKS equation was estimated to be $0.78,0.70,0.67$, and 0.62 in corresponding added salt ionic strength $(0.01,0.03,0.06$, and $0.10 \mathrm{~mol} / \mathrm{L})$ [113].

4.6. Chemical Reactivity. Chitosan has three reactive groups, that is, primary (C-6) and secondary (C-3) hydroxyl groups on each repeat unit and the amino (C-2) group on each deacetylated unit. These reactive groups are readily subject to chemical modifications to alter mechanical and physical properties of chitosan. The typical reactions involving the hydroxyl groups are etherification and esterification. Selective $O$-substitution can be achieved by protecting the amino groups during the reaction [71]. The presence of a nucleophilic amino group allows for selective $N$-substitution, such as $N$-alkylation and $N$-acylation by reacting chitosan with alkyl halides and acid chlorides, respectively [71, 75, 114-117]. The alternative method for the $N$-alkylation is a reductive alkylation, where the amino group is converted to an imine with an aldehyde or ketone, and subsequently reduced to an $N$-alkylated derivative [26, 70, 76, 118-120].

4.7. Film-Forming Properties. In recent years, increasing interest in edible films has developed mainly due to concern over the disposal of conventional synthetic plastic materials derived from petroleum. Degradation of plastics requires a long time and most of them end up overburdening on landfill. Conversely, edible films from renewable agriculture products not only are degraded readily after their disposal, but also can extend the food shelf life, thus improving the quality of food. Among various available edible film materials, considerable attention has been given to chitosan because of its unique properties. It has been extensively studied for applications as films or membranes. These films can be described as biofilms with a homogeneous matrix, stable structure, good water barrier, and mechanical properties [121-124]. The functional properties of chitosan films are improved when chitosan is combined with other film-forming materials. Hoagland and Parris [125] prepared chitosan-pectin laminated films by interaction between the cationic groups on chitosan with the anionic groups on pectin. Hosokawa et al. [126] reported that when biodegradable films were made from chitosan and homogenized cellulose oxidized with ozone the number of carbonyl and carboxyl groups on the cellulose interacting with the amino groups on the chitosan increased. The water resistance of chitosan film was ameliorated by the incorporation of hydrophobic materials such as fatty acids to enhance the film's hydrophobicity [127]. Starch has been used to produce biodegradable films to partially or entirely replace plastic polymers because of its low cost and renewability. However, a wide application of starch film is limited by its water solubility and brittleness [128, 129].

4.8. Gelling Properties. Hydrogels are three-dimensional networks that swell in water and aqueous solutions. These materials, based on both natural and synthetic polymers, are currently attracting a great deal of interest as bioactive molecules and in tissue engineering. Among natural biopolymers of interest, chitosan stands out due to its unique combination of favorable properties such as hydrogel forming. Chitosan hydrogels can be divided into two classes: physical and chemical. Chemical hydrogels are formed by irreversible covalent links, whereas physical hydrogels are formed by various reversible links. For various reasons, physically cross-linked hydrogels have attracted increasing attention as bioactive compounds.

The preparation and characterization of a few hydrogels of chitosan have been reported, such as thermoreversible chitosan-oxalate, chitosan-aldehyde gels [130-132], and chitosan-alginate [133]. So far, no simple ionic and nontoxic cross-linking agent has been found that gives reproducible chitosan gels at low concentrations, such as calcium ions for gelling of alginates. However, aqueous chitosan gels crosslinked with molybdate polyoxy-anions have been reported, resulting in transparent, thermoirreversible gels that are able to swell several times their original size in aqueous solutions, depending on the ionic strength [134]. Different chitosan gels made with covalent cross-linking have been reported, with cross-linking with glutaraldehyde being the most widely applied $[135,136]$. In addition, an enzymatic gelling system with chitosan has been reported [137-139].

4.9. Ion Binding. Chitosan is proved to have the best chelating properties among other natural polymers [140]. Responsible for complex formation are amino groups of chitosan, in which nitrogen is a donor of electron pairs, although hydroxyl groups may also participate in sorption. The mechanism of combining these reactive groups with ions of metals is much differentiated and can depend on the ion type, $\mathrm{pH}$, and also on the main components of the solution. The complexes formation could be also described based on Lewis acid-base theory: metal ion (acting as the acid) is the acceptor of a pair of electrons given by chitosan (acting as the base).

In relation to food applications of chitosan, its application as a cholesterol-lowering agent $[141,142]$ and more controversial use as a weight-reducing agent, knowledge on the selective binding of essential metal ions to chitosan is important. Most studies of ion binding to chitosan have been aimed at determining whether chitosan binds to a given ion, whereas only a few studies have involved determining the selectivity of binding of different ions to chitosan. Rhazi et al. [143] determined the selectivity of mixtures of the ions $\mathrm{Cu}^{2+}>\mathrm{Hg}^{2+}>\mathrm{Zn}^{2+}>\mathrm{Cd}^{2+}>\mathrm{Ni}^{2+}>\mathrm{Co}^{2+}=\mathrm{Ca}^{2+}$, using potentiometric and spectrometric methods. Vold et al. [144] reported the selectivity of different chitosans in binary mixtures of $\mathrm{Cu}^{2+}, \mathrm{Zn}^{2+}, \mathrm{Cd}^{2+}$, and $\mathrm{Ni}^{2+}$, showing that chitosan could bind $\mathrm{Cu}^{2+}$ in large excess of the other metal ions. Recent years, chitosan-metal complexes attracted 
great interests for their potential use in agriculture, medical industry, and food industry [145-148]. It is well known that both chitosan and metals such as $\mathrm{Ag}+, \mathrm{Cu}^{2+}, \mathrm{Ni}^{2+}$, and $\mathrm{Zn}^{2+}$ have the properties of disinfection and bactericide [147, 149]. After chitosan binds to metal ions through nitrogen and or oxygen, the bindings are likely to leave some potential donor atoms free and these free donor atoms enhance the antimicrobial activity [148]. So it stands a good chance that chitosan-metal complexes exhibit enhanced ability of the antimicrobial activity of chitosan molecule, which will be very favorable to their applications in agriculture, medical industry, and food industry $[147,148]$.

4.10. Emulsification. Even though chitosan alone does not produce emulsions, Cho et al. [150] reported that emulsifying capacity of egg yolk increased with the addition of chitosan. At a concentration of $0.5 \%$, better emulsifying capacity was observed compared with at 0.1 or $0.3 \%$ chitosan. In general, chitosan emulsions tend to be very stable under temperature changes and aging. With viscosity, the DA is reported to be a determining factor in the emulsification properties of chitosan. The protein solution containing chitosan with intermediate DDA produces less effective emulsion compared with that containing chitosan with higher DDA. The optimum chitosan DDA for sunflower oil emulsification is 81 and 89 as reported by Del Blanco et al. [151] and Rout [152], respectively.

\section{Modification of Chitosan Structure and Properties}

Chemical modifications of chitosan are increasingly studied as it has the potential of providing new applications. With regard to its unique properties such as biocompatibility, biodegradability, and no toxicity to mammals, it is widely used in fields like biotechnology, pharmaceutics, cosmetics and agriculture. In particular the antimicrobial activities of chitosan and its derivatives have aroused considerable recent interest. Unfortunately, in spite of the chitosan advantages, the poor solubility, low surface area, and porosity of chitosan are the major limiting factors in its utilization. Its solubility is limited at a pH higher than 6.5 where chitosan starts to lose its cationic nature. This problem is probably the major limiting factor for chitosan utilization, that is, its application in biology, since many enzyme assays are performed at neutral $\mathrm{pH}$. If water-soluble chitosan would be easily accessible, it is expected that the biological and physiological potential would increase dramatically.

Chitosan can be modified by physical or chemical processes in order to improve the mechanical and chemical properties. Chitosan is a multinucleophilic polymer due to the presence of the amino group at C-2 and hydroxyl groups at $\mathrm{C}-3$ and $\mathrm{C}-6$ in the GlcN residue. Chitosan membrane is swollen in water; the amino groups may be protonated and leave the hydroxide ions free in water, which may contribute to the ionic conduction in the membrane. The initial sites where substitution occurs are the more nucleophilic amino groups. However, the experimental conditions and protection of the amino groups reduce the intermolecular hydrogen bonding and creates space for water molecules to fill in and solvate the hydrophilic groups of the polymer backbone [75]. For introducing alkyl or substituted alkyl groups selectively at the amino groups, reductive alkylation is the most reliable procedure. Chitosan is treated with an aldehyde to give an imine (Schiff base), which is easily converted into an $N$-alkyl derivative by reduction with sodium borohydride or sodium cyanoborohydride [76, 78, $119,120,153,154]$. These reactions are facile; the DSs are generally high and the products are soluble in water or dilute acids. The chitosan derivatives mentioned in the literatures showed that one can differentiate specific reactions involving the $-\mathrm{NH}_{2}$ group at the $\mathrm{C}-2$ position or nonspecific reactions of $-\mathrm{OH}$ groups at the $\mathrm{C}-3$ and $\mathrm{C}-6$ positions (especially esterification and etherification) $[26,155-158]$. The positive charges on chitosan can also participate in ionic interactions, particularly with polyanions such as alginate and pectin. The complexes formed by electrostatic interaction between $\mathrm{COO}^{-}$or $\mathrm{SO}_{4}{ }^{--}$and $\mathrm{NH}_{4}{ }^{+}$[159] have been proposed for the recovery of suspended solids from aqueous food processing streams $[160,161]$ that can be used for animal feed.

Hydroxyalkyl chitosans are usually obtained in reactions of chitosan with epoxides. Depending on the reaction conditions ( $\mathrm{pH}$, solvent, and temperature); the reaction may take place predominantly at the amino or hydroxy groups giving $\mathrm{N}$-hydroxyalkyl- or $\mathrm{O}$-hydroxyalkyl chitosans or a mixture of both types. Under neutral and acidic conditions, $N$-hydroxyalkyl chitosan is preferred, leading to DS value $<2$. However, under alkaline conditions, the strongly nucleophilic oxygen ions will react much faster, resulting in $\mathrm{O}$-hydroxyalkyl chitosan with DS values $>2$ $[26,162,163]$.

Acylation of chitosan was the usual method involving reacting chitosan under homogeneous reaction conditions with either an acid chloride or acid anhydride [164]. Acylation was shown to proceed smoothly at the free amino groups preferentially and then more slowly at the hydroxyl groups [164]. Complete $N$-acylation has been achieved by treating chitosan with cyclic acid anhydrides in aqueous homogeneous media at $\mathrm{pH} 4$ to 8 . Some of the resulting $N$ carboxyacyl chitosans were successfully converted into the corresponding imido forms by thermal dehydration [165]. $\mathrm{N}$-acetylation of chitosan can be controlled when carried out in aqueous acetic acid solutions or in a highly swollen gel state in pyridine. With this gel, 50\% $N$-acetylation was achieved, and the product was found to be soluble in neutral water $[166,167]$. In case the swelling of chitosan is not sufficient, even the product with a similar DA does not give a homogeneous solution in water. Furthermore, no appreciable degradation is expected during the acetylation, and hence water-soluble chitosans with desired MWs can be prepared. Partial acetylation is also possible in homogeneous solutions in aqueous acetic acid/methanol [144] or in aqueous acetic acid [168] to give water-soluble products. The highest water solubility was again observed for a DA of 0.5. Under appropriate conditions similar to those for the benzoylation of chitin [169], chitosan was benzoylated (DS up to 2.5) with benzoyl chloride in methanesulfonic acid $[170,171]$. 
$\mathrm{N}$-saturated fatty acyl chitosan derivatives soluble in water, aqueous alkaline and acid solutions were prepared $[117,172,173]$. Acyl substitution was reported to take place on both $O$ - and $N$-positions under a large excess of acid chloride. The successful preparation of $\mathrm{N}, \mathrm{O}$-acyl chitosans in $\mathrm{MeSO}_{3} \mathrm{H}$ as solvent was performed by Sashiwa et al. $[79,174]$ and also in our laboratory [71]. In this method, chitosan was dissolved in $\mathrm{MeSO}_{3} \mathrm{H}$ and the acid chlorides were added dropwise. The homogenous mixture was neutralized with $\mathrm{NaHCO}_{3}$, then dialyzed and lyophilized to obtain the (N,Oacyl) chitosan derivatives with $O$-substitution as a major product. A noteworthy point is that both moderate substitution of $\mathrm{N}, \mathrm{O}$-acyl groups and moderate MW are important factors in obtaining highly biologically active compounds. Although the selective $\mathrm{O}$-acylation of chitosan in $\mathrm{MeSO}_{3} \mathrm{H}$ (owing to the salt formation of the primary amino group with $\mathrm{MeSO}_{3} \mathrm{H}$ ) was reported [175], the detailed chemical structure and the protecting effect of $\mathrm{MeSO}_{3} \mathrm{H}$ on the amino group are not clear yet. The preparation of $O, O$-didecanoyl chitosan was also reported through a protected $\mathrm{N}$-phthaloyl chitosan as intermediate [176]. However, this method needs several steps for the protection and deprotection of the $\mathrm{N}$ phthaloyl groups [177]. Some $N$-carboxyacyl chitosans were also prepared by reaction of chitosan with intramolecular carboxylic anhydrides including maleic, glutaric, phthalic, and succinic $[115,165,178]$. As related compounds, some cyclic phthalimido derivatives of chitosan were reported [179]. In addition, $N$-carboxyacyl chitosans filaments were synthesized by suspended chitosan in methanol and carboxylic anhydrides were added $[116,180]$. These compounds are usable as new functional materials in many fields because of their hydrophilic and acidic properties.

Grafting of chitosan allows the formation of functional derivatives by covalent binding of a molecule, the graft, onto the chitosan backbone [181]. The properties of the resulting graft copolymers are controlled by the characteristics of the side chains, including molecular structure, length, and number [182]. The cross-linking agents can be of varying length and contain other functional groups than those involved in cross-linking [183]. Partial crosslinking by di/polyfunctional reagents enables the use of chitosan for metal adsorption in acidic medium. Several bior polyfunctional cross-linking agents such as glutaraldehyde [184-187], ethylene glycol diglycidyl ether [188, 189], glyoxal [190], epichlorohydrin [191, 192], benzoquinone [193], and cyclodextrin [194-196] have been used. The fact that the cross-linking agents cited before are neither safe nor environment friendly has led to the use of water-soluble crosslinking agents such as sodium trimetaphosphate, sodium tripolyphosphate, or carboxylic acids [197].

One of the important strategies to increase both the solubility and positive charge density of chitosan is based on the introduction of quaternary ammonium groups into chitosan. This modification has got the commonly accepted term "quaternization of chitosan". Thus, derivatives soluble in water and in both acidic and basic physiologic circumstances may be good candidates for the polycationic biocides [198, 199]. Many efforts to synthesize quaternized chitosan derivatives have been reported. For example, Muzzarelli and Tanfani [157] reported the formation of $N, N$ dimethyl chitosan and the preparation of $N, N, N$-trimethyl chitosan iodide with formaldehyde and sodium borohydride. Trimethyl chitosan ammonium iodide was also obtained by reaction of a low acetyl content chitosan with methyl iodide and sodium hydroxide under controlled conditions [200, 201]. Water-soluble quaternary ammonium salts of $N, N, N-$ trimethyl, $N$ - $N$-propyl- $N, N$-dimethyl, and $N$-furfuryl- $N, N$ dimethyl chitosans were also prepared by reacting of $\mathrm{N}$ alkyl chitosan derivatives with methyl iodide $[109,202]$. Stepnova et al. [203] discovered a new, smooth, and one-step method for preparation of quaternized chitosans by means of reaction with betaine in the presence of the coupling reagent 2-ethoxy-1-ethoxycarbonyl-1,2-dihydroquinoline in aqueous media at $\mathrm{pH} 5.5 \pm 0.5$. This reaction results in preparation of $\mathrm{N}$-((trimethylammonio)acetyl) chitosan chloride and its amphiphilic derivatives. Other derivatives of quaternary chitosans as water-soluble and antimicrobial agents were recently prepared in our laboratory based on three-step process [70]. Schiff bases were firstly synthesized by the reaction of chitosan with aliphatic aldehydes followed by a reduction with sodium borohydride to form $\mathrm{N}$ alkyl chitosans. N,N,N-dimethyl alkyl chitosans were then obtained by a reaction of chitosan containing $N$-butyl, (pentyl), -hexyl, -heptyl, and -octyl substituents with methyl iodide.

The $-\mathrm{OH}$ and $-\mathrm{NH}_{2}$ groups on the skeleton of chitosan are good ligands to coordinate with transition metal ions to get chitosan-metal complexes [146-148]. Moreover, the amine group of chitosan is modified using many chemical methods including chitosan 6-O-sulfate [204, 205], $N$-sulfated chitosan [206], and $N$-methylene phosphonic chitosans $[207,208]$. So the functional groups of chitosan are easily modified by many organic reactions: tosylation [209], alkylation [210], carboxylation [211], sulfonation [205], Schiff base [212], and quaternary salt [157].

\section{Application of Chitosan in Crop Protection}

6.1. Chitosan and Its Derivatives as Antimicrobial Agents against Plant Pathogens (In Vitro Studies). The enormous increase in the number of relevant research papers and patents revealed a surprisingly high level of chitosan research activity from both academic and industrial scientists. Many literatures reported that chitosan and its derivatives have antimicrobial and plant-defense elicit function [6, 213-218]; therefore, these compounds are considered as useful pesticides in the control of plant diseases. The ideal antimicrobial polymer should possess the following characteristics: (1) easily and inexpensively synthesized, (2) stable in longterm usage and storage at the temperature of its intended application, (3) soluble in water or neutral media, (4) does not decomposed to and/or emit toxic products, (5) should not be toxic or irritating to those who are handling it, (6) can be regenerated upon loss of activity, and (7) biocidal to a broad spectrum of pathogenic microorganisms in brief times of contact [219]. 
Numerous studies on the antimicrobial activity of chitosan and its derivatives against most economic plant pathogens have been investigated $[26,70,71,76-78,145$, 220-227] and reviewed $[6,8,10,100,218,228-231]$. Their antimicrobial activity has received considerable interest due to the problems associated with harmful synthetic antimicrobial agents $[221,232]$. Chitosan's inhibition was observed on different development stages such as mycelial growth, sporulation, spore viability and germination, and the production of fungal virulence factors. It has been commonly recognized that the antimicrobial activity depends on the MW, DA, pH of chitosan solution and, of course, the target organism [202, 226, 232-244]. The natural antimicrobial characteristics of chitosan and its derivatives have resulted in their use in commercial disinfectants. Chitosan has several advantages over other types of disinfectants in that it possesses a high-antimicrobial activity, a broad spectrum of activity, and a low toxicity for mammalian cells [245]. Generally yeasts and moulds are the most sensitive group, followed by gram-positive bacteria and finally gram-negative bacteria [223]. The inhibitory activity was higher at $\mathrm{pH} 6.0$ $\left(p K_{a}\right.$ value of chitosan $\left.=6.2\right)$ than $\mathrm{pH} 7.5$, when most amino groups are in the free base form.

Variation in sensitivity between closely related micoorganisms was illustrated in an experiment in which plant pathogenic fungi were screened for sensitivity to chitosan in liquid media [246]. One Cytosporina sp. isolate was completely inhibited by $75 \mathrm{mg} / \mathrm{L}$ chitosan, while a second isolate of the same genus was unaffected by $1000 \mathrm{mg} / \mathrm{L}$. Chien and Chou [247] noted that the antifungal activity of chitosan depends on the type, concentration and test organism. For example, at $0.1 \%$, chitosan of $92.1 \mathrm{kDa}$ showed a higher growth inhibition of $76.2 \%$ on $P$. italicum than did chitosan of $357.3 \mathrm{kDa}(71.4 \%)$, while at $0.2 \%$, the antifungal activity exerted by chitosan of $357.3 \mathrm{kDa}$ was higher than chitosan of $92.1 \mathrm{kDa}$ against $P$. italicum.

A report by Benhamou et al. [248] indicated that chitosan derived from crab-shell at concentrations of 500 and 1000 $\mathrm{mg} / \mathrm{L}$ was effective in reducing disease incidence caused by F. oxysporum f. sp. radicis-lycopersici. At the same time El Ghaouth et al. [249] revealed that chitosan was effective in inhibiting mycelial growth of $P$. aphanidermatum completely at a concentration of $400 \mathrm{mg} / \mathrm{L}$. In our laboratory, we found that chitosan concentration increased $(750-6000 \mathrm{mg} / \mathrm{L})$, the radial growth of $A$. alternata, $B$. cinerea, Colletrotichum gloeosporioides, and Rhizopus stolonifer was decreased [250]. The same effect was reported on Sclerotinia sclerotiorum when chitosan concentrations increased from $1 \%$ to $4 \%$ [251]. Other studies showed a linear decrease of growth of $R$. solani as the chitosan concentration gradually increased from 0.5 to $6.0 \mathrm{mg} / \mathrm{mL}$ [252]. However, a complete growth inhibition was recorded against $F$. oxysporum, $R$. stolonifer, P. digitatum, and C. gloeosporioides at concentrations of 3\% $[253,254]$.

The fungicidal activity of three commercial chitosan samples $\left(3.60 \times 10^{5}, 6.11 \times 10^{5}\right.$, and $\left.9.53 \times 10^{5} \mathrm{Da}\right)$ was tested in our laboratory against plant pathogenic bacteria of Agrobacterium tumefaciens, Corynebacterium fascians, Erwinia amylovora, E. carotovora, Pseudomonas solanacearum, and Sarcina lutea [250]. The results indicated that chitosans of $6.11 \times 10^{5}$ and $9.53 \times 10^{5}$ Da were more potent in bactericidal activity than $3.60 \times 10^{5}$ Da chitosan and a chitosan of $9.53 \times 10^{5} \mathrm{Da}$ exhibited a good antibacterial potency especially against $C$. fascians with MIC $500 \mathrm{mg} / \mathrm{L}$. Moreover, three different MWs $\left(0.5 \times 10^{4}, 3.7 \times 10^{4}\right.$, and $\left.5.7 \times 10^{4} \mathrm{Da}\right)$ chitosan were prepared in our laboratory from a commercial sample of chitosan $\left(2.9 \times 10^{5} \mathrm{Da}\right)$ and evaluated against bacteria of A. tumefaciens and E. carotovora and fungi of $A$. alternata, B. fabae, F. oxysporum, and R. stolonifer [255]. Chitosan of $0.5 \times 10^{4} \mathrm{Da}$ exhibited a good antibacterial potency against $A$. tumefaciens with MIC $2600 \mathrm{mg} / \mathrm{L}$, while chitosan of $3.7 \times 10^{4} \mathrm{Da}$ was the most active against $E$. carotovora with MIC $950 \mathrm{mg} / \mathrm{L}$. The antifungal activity was increased with decrease of the MW and chitosan of $0.5 \times 10^{4} \mathrm{Da}$ exhibited a high antifungal potency against $B$. fabae, F. oxysporum, and $R$. stolonifer while the fungus of $A$. alternata was more sensitive to a chitosan of $3.7 \times 104 \mathrm{Da}$. This fact is in agreement with studies of Kim and Rajapakse, [256] and Zhang et al. [257] who reported that oligochitosans, obtained by hydrolysis or degradation of chitosan, was not only water-soluble but also have shown to be more effective than chitosan. Interestingly, oligochitosan (hexamer unit) that elicited maximal pisatin formation also exhibited higher antifungal activity against $F$. solani than the lower with degree of polymerization [223]. Xu et al. [258] added that the oligochitosans prepared by enzymatic depolymerization were more effective than the original chitosan in inhibiting mycelial growth of nine phytopathogens F. graminearum, Phytophthora capsici, Verticillium dahliae, A. solani, B. cinerea, C. orbiculare, Exserohilum turcicum, F. oxysporum, and Pyricularia oryzae and their inhibition on different stages in life cycle was observed. Hirano and Nagao [259] testing high- and low-molecularweight chitosan on different fungal species and they found that the best fungicidal activity on mycelia occurred in media supplemented with low-molecular-weight chitosan. However, Bautista-Baños et al. [260] indicated that no differences in the fungicidal pattern among the three different types of chitosan, whereas there was a higher fungicidal effect as chitosan concentration increased $(0.5-2.0 \%)$. Meng et al. [261] reported that both of chitosan $(350 \mathrm{kDa})$ and oligochitosan $(6 \mathrm{kDa})$ strongly inhibited spore germination and mycelial growth of two phytopathogenic fungi $A$. kikuchiana Tanaka and Physalospora piricola Nose. El Ghaouth et al. [215] found that a chitosan at concentrations ranged from 750 to $6000 \mathrm{mg} / \mathrm{L}$ was very effective in inhibiting spore germination and germ tube elongation of $B$. cinerea and $R$. stolonifer. Furthermore, this biopolymer at a concentration greater than $1500 \mathrm{mg} / \mathrm{L}$ induced morphological changes in R. stolonifer. Hernández-Lauzardo et al. [262] confirmed that the spore morphology of $R$. stolonifer presented variations in area, form, and optical density in chitosan solutions.

Control of two sapstain fungi Leptographium procerum and Sphaeropsis sapinea by a combination of chitosan or chitosan oligomer and an albino strain of Trichoderma harzianum was tested by Chittenden and Singh [263]. There was no mycelial growth of the fungi regardless of chitosan concentrations used when either L. procerum or $S$. sapinea were simultaneously inoculated with T. harzianum. 
However, the dose response of chitosan or chitosan oligomer was apparent when T. harzianum was not simultaneously inoculated with test fungi but introduced later. There was a greater growth reduction at higher concentrations $(0.075-$ $0.1 \%$ ) of chitosan, and overall chitosan oligomer was more effective than chitosan aqueous solution. Chitosan alone was able to restrict or delay the germination of spores but the combination of chitosan and T. harzianum inhibited spore germination and hence colony formation of test fungi regardless of time delay.

In addition, chitosan shows an antiviral activity against plant viruses. It was shown that chitosan inhibited the productive infection caused by the bacteriophage, the efficiency of inhibition of bacteriophage depending directly on the final concentration in the medium [264]. Major factors of suppressing phage infections by chitosan are phage particle inactivation and inhibition of bacteriophage reproduction at the cellular level. Evidently, chitosan may be used for induction of phagoresistance in industrial microorganism cultures to prevent undesirable phagolysis caused by inoculum contamination by virulent bacteriophages or by spontaneous prophage induction in lysogenic culture.

According to the data published on the antifungal and antibacterial activities of chitosan which indicated low activity observed against plant pathogens, several research groups have started to modify a chitosan molecule to produce high-antimicrobial active compounds. For examples, $N$-sulfonated and $N$-sulfobenzoyl chitosans [234], N,N,Ntrimethyl chitosan [109], N,O-acyl chitosans [71, 79], Oacyl chitosans [77], hydroxyethyl acryl chitosan [265], dimethylpiperazine and trimethylpiperazine chitosans [266], carboxymethyl chitosans [267, 268], acyl thiourea chitosans [269], chitosan $N$-betainates [270], N-succinoyl chitosans [225], and $N$-heterocyclic chitosans [76]. We have prepared in our laboratory some of chitosan derivatives through the reductive amination reaction as described by Borch et al. [271] with various aldehydes. We noted that $N$ alkylation or -arylation of chitosan with aliphatic or aromatic aldehydes, respectively, effectively enhanced the antifungal activity of chitosan $[77,78,119,120]$. For example, $N$ - $(o, p-$ diethoxybenzyl)chitosan was the most active one with $\mathrm{EC}_{50}$ of 400 and $468 \mathrm{mg} / \mathrm{L}$ for F. oxysporum and P. debaryanum, respectively. With the same methods and techniques, but different kinds of aldehydes, we have synthesized a series of $N$-benzyl chitosan derivatives and the fungicidal assessment has been investigated against $B$. cinerea and $P$. grisea [119]. The data revealed that $N$-(o,o-dichlorobenzyl) chitosan was the most active compound against $B$. cinerea with an $\mathrm{EC}_{50}$ of $520 \mathrm{mg} / \mathrm{L}$. However, $N$-(benzo[d][1,3]dioxol5-ylmethyl) chitosan, and $N$-(methyl-4H-chromen-4-one) chitosan as new $N$-(heterocyclic) chitosan derivatives were the most active against $P$. debaryanum and $F$. oxysporum [76]. Guo and coworkers [222] added that the Schiff bases of chitosan and the $N$-substituted chitosan derivatives had a slight activity against $B$. cinerea Pers., and the inhibitory indices were $26.8 \%, 33.5 \%, 39.3 \%$, and $32.3 \%$ at 1000 ppm, respectively, compared with $45.4 \%$ at chitosan. Previously, we synthesized derivatives of $\mathrm{N}, \mathrm{O}$-acyl chitosans [71] and the data indicated that $N, O-(p$-chlorobutyryl $)$ chitosan, N,O-decanoyl chitosan, N,O-cinnamoyl chitosan and $N, O-(p$-methoxybenzoyl $)$ chitosan were the most active compounds against $B$. cinerea $\left(\mathrm{EC}_{50}=430,440,450\right.$ and $500 \mathrm{mg} / \mathrm{L}$, respect.) and were 12- to 13 -fold more active than the native chitosan $\left(\mathrm{EC}_{50}>3000 \mathrm{mg} / \mathrm{L}\right)$.

Previously Muzzarelli et al. [272] prepared five chemically modified chitosans and tested their antifungal activities against Saprolegnia parasitica. Results indicated that, as for the chitosan-bearing broth assay, S. parasitica did not grow normally; on the first day for methylpyrrolidinone chitosan and $N$-phosphonomethyl chitosan and on the second day for $N$-carboxymethyl chitosan, a tightly packed precipitate was present at the bottom of the test tubes instead of the fluffy fungal material as in the control. In contrast, $\mathrm{N}$ dicarboxymethyl chitosan seemed to favor fungal growth, while dimethylaminopropyl chitosan did not significantly differ from the control.

$N, N, N$-dimethylalkyl chitosans as quaternary and watersoluble chitosan compounds were recently prepared in our laboratory to test their antimicrobial activities against the most economic plant pathogenic bacteria $A$. tumefaciens and E. carotovora and fungi B. cinerea, F. oxysporum, and $P$. debaryanum [70]. Quaternary chitosans enhanced the antibacterial activity and $N, N, N$-dimethylpentyl chitosan was the most active with MIC 750 and $1225 \mathrm{mg} / \mathrm{L}$ against $A$. tumefaciens and E. carotovora, respectively. However, both of $N, N, N$-dimethylpentyl chitosan and $N, N, N$-dimethyloctyl chitosan were significantly the highest in fungal mycelial growth inhibition of $B$. cinerea, $F$. oxysporum and $P$. debaryanum. In addition, spore germination of $B$. cinerea and F. oxysporum was significantly affected with the compounds at the tested concentrations and the inhibition activity was increased with an increase in the chain length of the alkyl substituent. Previously Hernández-Lauzardo et al. [236] reported that spore germination of $R$. stolonifer was affected by different MWs chitosan $\left(1.74 \times 10^{4}, 2.38\right.$ $\times 10^{4}$ and $\left.3.07 \times 10^{4} \mathrm{Da}\right)$. They found that chitosan of $1.74 \times 10^{4}$ and $2.38 \times 10^{4} \mathrm{Da}$ markedly reduced spore germination, but no significant effects were found among the tested concentrations $(1.0,1.5$, and $2.0 \mathrm{mg} / \mathrm{mL})$. However, they observed a complete inhibition of spore germination with a chitosan of $3.07 \times 10^{4} \mathrm{Da}$. Recently, the effect of $N$-(benzyl) chitosan derivatives on spore germination of F. oxysporum was evaluated in our laboratory at 250, 500, and $1000 \mathrm{mg} / \mathrm{L}$ [78]. All the derivatives had better inhibition of spore germination, about threefold compared with chitosan. $N$-( $p$-dimethylaminobenzyl) chitosan, $N$ - $(p-$ ethylbenzyl) chitosan, $N$-(o-methoxybenzyl) chitosan, and $N$-(o,p-diethoxybenzyl) chitosan significantly exhibited high inhibition percentage $(>90 \%)$ of spore germination at $1000 \mathrm{mg} / \mathrm{L}$.

6.2. Chitosan and Its Derivatives in Plant Disease Control (In Vivo Studies). The plant protection activity of chitosan compounds have been well documented in many different plant systems [10]. The control diseases of chitosan include bacteria, fungi, and viral diseases. In this section, the effects of these compounds on several plants will be discussed. 
In 1980, Professor Hadwiger at Washington State University reported that oligochitosan can induce soybean against $F$. solani [273]. Oligochitosan from the F. solani f. sp. phaseoli cell walls could elicit defense reaction in pea pod tissue. Concentrations of oligochitosan as low as 0.9 and $3 \mathrm{mg} / \mathrm{mL}$ elicited phytoalexin induction and inhibited the germination of F. solani, respectively. This was the first publication of chitosan-induced plant resistance. From then, a series of excellent work was conducted in his laboratory. These creative researches led to an increased tide on the study of chitosan-induced plant defense.

The soilborne phytopathogenic fungi F. solani and C. lindemuthianum were inhibited by chitosan and $N$ (carboxymethyl) chitosan [274-276]. Benhamou et al. [248] added that chitosan concentrations of 0.5 and $1 \mathrm{mg} / \mathrm{mL}$ showed high plant protection from F. solani, when seed coating and soil amendment were performed. Although chitosan at $0.1 \mathrm{mg} / \mathrm{mL}$ induced a delay in disease development (root lesions visible by 4 days after inoculation), emergence of wilting symptoms occurred between 7 and 10 days after-inoculation, while death of about $80 \%$ of the plants was recorded 1 week later. F. acuminatum, Cylindrocladium floridanum, and other plant pathogens of interest in forest nurseries were inhibited by chitosan [277]. Similarly, Aspergillus flavus was completely inhibited in fieldgrowing corn and peanut [278]. Generally, chitosan has highantifungal activity, but it is less effective against fungi with a chitin or chitosan component in their cell walls [246]. Part of the effect observed by chitosan on the reduction of soilborne pathogens comes from the fact that it enhances plant defense responses. The other part is linked to the fact that it is composed of polysaccharides that stimulate the activity of beneficial micro-organisms in the soil such as Bacillus, fluorescent, Pseudomonas, actinomycetes, mycorrhiza, and rhizobacteria. This alters the microbial equilibrium in the rhizosphere disadvantaging plant pathogens. Beneficial organisms, on the other hand, are able to compete them through mechanisms such as parasitism, antibiosis, and induced resistance [279-284].

Great advancement of chitosan on rice disease control has been achieved in recent years. In 2002, Agrawal and coworkers reported the effect of chitosan in initiating defense response in the leaves of rice for the first time [285]. After treatment with $0.1 \%$ chitosan, necrotic streaking was clearly observed on the upper side of rice leaves. Enhanced defense against rice blast pathogen, Magnaporthe grisea 97-23-2D1, was observed in $H 7 S$ rice seedlings treated with oligochitosan. In this experiment, $5 \mathrm{mg} / \mathrm{L}$ oligochitosan solution showed the best effect and the disease control was more than 50\% [286]. Chitosan was tested in rice production by Boonlertnirun et al. [287] and its application by seed soaking and soil application four times throughout cropping season significantly increased rice yield over the other treatments. However, application by seed soaking and spraying the foliar four times tended to show ability on disease control. Zeng and Shi [288] developed a new type of organic rice seed coating agent using liquid-based polymeric adhesives. By using chitosan as the main raw material, modified with sodium hydroxide and polymerised with plant growth regulators and other additives, the novel seed coating agent is a safer, cheaper, and more environmentally friendly alternative. Results of antifungal tests showed that the antifungal efficiency of the seed-coating agent was increased with increasing amount of dosage; a $1: 20$ concentration was the best for inhibiting growth of the two phytopathogens $R$. solani and F. moniliforme.

Wheat is another important source of staple food, especially in cold countries; therefore, Russian scientists conduct more research in this area. Studies conducted on wheat infection with Bipolaris sorokiniana indicated that oligochitin with a MW of $5-10 \mathrm{kDa}$ and the $\mathrm{DA}$ of $65 \%$ has good effect on controlling wheat disease [289, 290]. The ability of oligochitosan to promote wheat resistance to pathogenic toxin was also validated [291]. Chitosan treatment (2$8 \mathrm{mg} / \mathrm{mL}$ ) of wheat seeds (two cultivars of spring wheat (Norseman and Max)) significantly improved seed germination to recommended seed certification standards ( $>85 \%)$ and vigour at concentrations $>4 \mathrm{mg} / \mathrm{mL}$ by controlling seedborne F. graminearum infection. The germination was $<80 \%$ in the control and $>85 \%$ in chitosan-treated seeds. The reduction of seed-borne $F$. graminearum was $>50 \%$ at higher chitosan treatments compared with control [292].

Tobacco is an important economic crop and a model plant for research. Many reports reveal that chitosan can induce tobacco's resistance to tobacco mosaic virus, tobacco necrosis virus, and Phytophthora parasitica. For example, Falcon studied the effect of different sizes and DA of chitosan derivatives on tobacco protection against $P$. parasitica [293]. The results of their experiment showed that different chitosans have distinct effects on this disease control, though less acetylated chitosan were better for inhibition of $P$. parasitica growth, partially acetylated chitosan were more effective in protecting tobacco against this pathogen by systemic induction of plant immunity.

Sclerotinia rot is the most harmful disease on oilseed rape production. The inducing resistance of oligochitosan to Sclerotinia sclerotiorum on Brassica napus was studied [294]. However, oligochitosan did not affect the radial growth of S. sclerotiorum colonies; it reduced the frequency and size of rot compared with controls when applied to oilseed rape before inoculation. The best pretreated time was 3 days before inoculation, and the best inducing resistance concentration of oligochitosan was $50 \mu \mathrm{g} / \mathrm{mL}$. Oligochitosan can be modulated into steady colloid solution, so it can be used as a seed-coating agent. It does not influence the seed sprout and emerge, but can obviously suppress the emergence of S. sclerotiorum; the control rate of three species of rape was 34.19-44.10\% [295].

Chitosan was shown to inhibit the systemic propagation of viruses and viroids throughout the plant and to enhance the host's hypersensitive response to infection. Potato is a tuberous crop from the perennial Solanum tuberosum of the Solanaceae family. It is an essential crop in the world. The effect of the chitosan-induced resistance to viral infection was investigated in potato plants. The plants were sprayed with different molecular weights of chitosan solution $(1 \mathrm{mg} / \mathrm{mL})$ and the greatest antiviral activity was shown by chitosan of $120 \mathrm{kDa}$. In another experiment, potatoes were 
infected with potato virus $\mathrm{X}$ after chitosan pretreatment. It was found that chitosan treatment significantly decreased the number of systemically infected plants compared to control, and the treated leaves also accumulated less amount of virus than the control leaves [296]. The antiviral activity of chitosan depends on the average degree of polymerization, the degree of $N$-deacetylation, the positive charge value, and the character of the chemical modifications of the molecule. Possible mechanisms of suppressing viral infections by chitosan are also discussed [264, 296-301]. Chitosan applied by spraying or inoculating leaves protected various plant species against local and systemic infection caused by alfalfa mosaic virus, tobacco necrosis virus, tobacco mosaic virus, peanut stunt virus, cucumber mosaic virus, and potato virus $\mathrm{X}[300,301]$. The ability of chitosan to suppress viral plant infections does not depend on the virus type because chitosan affects the plant itself by inducing resistance to the viral infection. Imitating the contact of the plant with a phytopathogen, chitosan induces a wide spectrum of protective reactions in the plant, which limit a systemic spread of the viruses and viroids over the plant and lead to the development of systemic acquired resistance [296-301].

The effect of oligochitosan and oligochitin on gray mould caused by $B$. cinerea in cucumber plants were evaluated by Ben-Shalom et al. [302]. It was shown that oligochitosan and oligochitin had different effects on this cucumber-pathogen interaction. Although complete inhibition of Botrytis conidia germination was found at $50 \mathrm{ppm}$ chitosan solution in vitro, chitosan also controlled the gray mould in treated plants compared with control plants. But there was no effect of oligochitin on both pathogen growth on PDA and leaves. Besides this fungicidal effect, spraying chitosan 1, 4, and $24 \mathrm{~h}$ before inoculation with $B$. conidia decreased gray mould by 65,82 , and $87 \%$, respectively. However, spraying chitosan on the leaves decreased gray mould incidence only by $52 \% 1 \mathrm{~h}$ after inoculation. These results suggest that the antifungal and elicitor activity of chitosan are both necessarily for the control of gray mould in cucumber [302]. P. aphanidermatum (Edson) Fitzp is an aggressive and economically important pathogen in greenhouse-grown cucumbers. Especially in substrates like rockwool which exhibit high water retention capacity, it can flourish and spread rapidly by zoospores. The pathogen causes severe root and crown rot, which result in wilting and death of plants. A recent paper showed that chitosan cannot induce defense to this pathogen when used alone. But the application of chitosan in combination with Lysobacter enzymogenes $3.1 T 8$ (a biocontrol bacterium) reduced the number of diseased plants by $50 \%-100 \%$ in four independent experiments relative to the Pythium control. [303, 304].

Vasyukova et al. [305] reported that low-molecularweight water-soluble chitosan $(5 \mathrm{kDa})$, obtained after enzymatic hydrolysis of native crab chitosan, was shown to display an elicitor activity by inducing the local and systemic resistance of $S$. tuberosum potato and Lycopersicon esculentum tomato to $P$. infestans and nematodes, respectively. Chitosan induced the accumulation of phytoalexins in tissues of host plants; decreased the total content; changed the composition of free sterols producing adverse effects on infesters; activated chitinases, $\beta$-glucanases, and lipoxygenases; stimulated the generation of reactive oxygen species. The activation of protective mechanisms in plant tissues inhibited the growth of taxonomically different pathogens (parasitic fungus $P$. infestans and root knot nematode Meloidogyne incognita). In addition, the potential of $B$. pumilus strain SE 34 in combination with chitosan, for inducing defense reactions in tomato plants inoculated with F. oxysporum, was studied [306]. A substantial increase in the extent and magnitude of the cellular changes induced by $B$. pumilus was observed when chitosan was supplied to bacterized tomato plants. These changes were characterized by a considerable enlargement of the callose-enriched wall appositions deposited onto the inner cell wall surface in the epidermis and the outer cortex.

Chitosan of $350 \mathrm{kDa}$ was more effective at $25^{\circ} \mathrm{C}$ than oligochitosan $(6 \mathrm{kDa})$ in controlling of the disease in pear fruit caused by two phytopathogenic fungi of A. kikuchiana Tanaka and Physalospora piricola Nose [261]. When treated with oligochitosan, pear fruit increased the activities of chitinase and b-1,3-glucanase. Differently, chitosan treatment significantly increased peroxidase activity of pear fruit. The results suggested that chitosan and oligochitosan triggered different mechanism for pathogenicity inhibition and disease control.

Chitosan compounds are used as biopesticides in many grape-producing countries. It was reported that oligochitosan (1500 Da and a DA of $20 \%$ ) at $200 \mu \mathrm{g} / \mathrm{mL}$ dramatically reduced the infection of grapevine leaves by Plasmopara viticola and B. cinerea. Dose-response experiments showed that maximum defense reactions and control effect of B. cinerea were achieved with $75-150 \mu \mathrm{g} / \mathrm{mL}$ [307-309]. Similarly, on apple and watermelon, chitosans can induce plant defense against canker and anthracnose.

Guan et al. [310] examined the use of chitosan to prime maize seeds. Although chitosan had no significant effect on germination under low temperatures, it enhanced germination index, reduced the mean germination time, and increased shoot height, root length, and shoot and root dry weights in two tested maize lines. In both tested lines, chitosan induced a decline in malonyldialdehyde content, altered the relative permeability of the plasma membrane and increased the concentrations of soluble sugars, proline, peroxidase, and catalase activities. In other studies, seed priming with chitosan improved the vigor of maize and wheat seedlings. It was also reported that such treatment led to an increase of seed resistance to certain diseases and improve their quality and/or their ability to germinate [292, 311]. Similarly, peanut seeds soaked in chitosan were reported to exhibit an increased rate of germination and energy, lipase activity, and gibberellic acid and indole acetic acid levels [312]. Ruan and Xue [313] showed that rice seed coating with chitosan may accelerate their germination and improve their tolerance to stress conditions. In carrot, seed coating helps restrain further development of Sclerotinia rot [251]. It has also been reported that chitosans can activate plant defense to disease on several other plants such as barley [314], pearl millet [315], carrot [316], sunflower [317], and coconut [318]. 
6.3. Chitosan and Its Derivatives in Postharvest Application. Fruits and vegetables deteriorate rapidly after harvest and in some cases do not reach consumers at optimum quality after transport and marketing. The main causes of their deterioration are dehydration, with the subsequent weight loss, color changes, softening, surface pitting, browning, loss of acidity, and microbial spoilage, among others. One of the potential approaches to extend the storability of these perishable commodities is to apply edible coatings or films on the surface, followed by a cold storage [319]. Therefore, the use of bioactive substances such as chitosan to control postharvest microbial diseases has attracted much attention due to imminent problems associated with chemical agents $[215,216,320]$. It has become a promising alternative treatment for fruits and vegetables due to its natural character, antimicrobial activity, and elicitation of defense responses $[321,322]$. Indeed, chitosan is an ideal preservative coating for fresh fruits and vegetables because of its film-forming and biochemical properties [323] and has led to prolonged storage life and controlled decay of several fruit crops [324]. Chitosan coating is likely to modify the internal atmosphere without causing anaerobic respiration, since chitosan films are more selectively permeable to $\mathrm{O}_{2}$ than to $\mathrm{CO}_{2}$ [325].

Strawberry is among the most perishable fruits and is vulnerable to physical injuries and microbial infection. El Ghaouth and coworkers [215, 326] investigated the effect of chitosan coating on decay and quality of strawberries. Fruits were inoculated with spore suspension of $B$. cinerea or $R$. stolonifer and subsequently dipped in chitosan solutions ( 1.0 and $1.5 \%$ in $0.25 \mathrm{~N} \mathrm{HCl}$ ). In both studies, chitosan coating significantly reduced the decay of strawberries compared with the control. Chitosan coating decreased the respiration rate of strawberries with a greater effect at higher concentration. The improved storability of fresh strawberries by chitosan-based coating also has been documented [319, 327-330].

$\mathrm{Li}$ and $\mathrm{Yu}$ [331] reported that chitosan significantly delayed the postharvest development of brown rot disease caused by Monilinia fructicola on peach fruit. Effects of chitosan coating on browning of litchi (Litchi chinensis) fruit were also investigated by several workers [332-334]. Chitosan coating, irrespective of concentration 1 and $2 \%$ dissolved in $2 \%$ glutamic acid delayed changes in contents of anthocyanins, flavonoids, and total phenolics. It also delayed the increase in polyphenol oxidase (PPO) activity, and partially inhibited the increase in peroxidase activity [332, 335]. Jiang et al. [333] also similarly observed that chitosan of $2 \%$ in $5 \%$ acetic acid coating delayed the decrease in anthocyanin content and the increase in PPO activity. Such effects of chitosan coating were also observed with peeled litchi fruit [336], longan fruit [337], and freshcut Chinese water chestnut vegetable [338]. Dependence of browning rate of chitosan-coated litchi fruit on the initial pericarp water content [332], pericarp $\mathrm{pH}$, and dehydration rate during storage [334] has been reported.

Penicillium is the most harmful citrus fruit postharvest pathogen and infects the fruit through microinjuries generated in the flavedo, during harvesting and processing. However, nowadays, consumers around the world demand high-quality food, without chemical preservatives, leading to increased effort in discovering new natural antimicrobials. Accordingly, the fungistatic effects of chitosan have been investigated. For example, coating of citrus fruit with chitosan was effective in controlling fruit decay caused by $P$. digitatum and P. expansum and chitosan of $15 \mathrm{kDa}$ at $0.2 \%$ was more effective in controlling the growth of fungi than chitosan of $357 \mathrm{kDa}$ [339].

Moreover, edible coatings can be used as a vehicle for incorporating functional ingredients such as antioxidants, flavors, colors, antimicrobial agents, and nutraceuticals [327, 340-342]. Several workers have endeavored to incorporate calcium [327, 328], vitamin E [327, 343], potassium [319], or oleic acid [330] into chitosan film formulation to prolong the shelf life and to enhance the nutritional value of fruits.

Gray mold and blue mold rots caused by $B$. cinerea and $P$. expansum, respectively, in sweet cherry fruit were reduced by preharvest spraying or postharvest dipping of chitosan [344]. Liu et al. [345] added that the control effects of chitosan on both fungi significantly decreased in tomato fruit at 5000 and $10000 \mathrm{mg} / \mathrm{L}$ and the gray mold was better controlled than blue mold. Previous investigations on chitosan coating of tomatoes have shown that it delayed ripening by modifying the internal atmosphere that reduced the decay [215, 216, 320]. Recently we investigated the effectiveness of different molecular weights chitosan on the gray mold caused by $B$. cinerea as in vivo in tomato fruit (Solanum lycopersicum L. var. lycopersicum) stored at different temperatures [220]. The treatments significantly reduced fungal decay and all compounds at concentrations of 2000 and $4000 \mathrm{mg} / \mathrm{L}$ exhibited complete fungal control in wound-inoculated fruit. In addition, chitosan had potential for the elicitation of defense markers, including total soluble phenolics, PPO activity and total protein content. This finding suggests that the effects of chitosan may be associated with direct fungitoxic properties against the pathogen, and the elicitation of biochemical defense responses in fruits [220]. After treatment with chitosan, various defense responses have been induced, including the elicitation of phenylalanine ammonia lyase (PAL) activity in grape berries $[324,346]$, chitinase, and $\beta$-1,3-glucanase in oranges, strawberries, and raspberries $[345,347,348]$.

\section{Factors Affecting Antimicrobial Activity of Chitosan}

The extent of the antimicrobial action of chitosan is influenced by intrinsic and extrinsic factors such as MW, DDA, $\mathrm{pH}$, temperature, solubility, derivatization, type of organism and so on. It is necessary to understand these factors for the effective application of chitosan and its derivatives as antimicrobial agents against plant pathogens.

7.1. Molecular Weight. Effect of chitosan MW on the antimicrobial activities has been explored and most investigators used the uncertain term of low MW (LMW) chitosan for a partially depolymerized chitosan not indicating exactly its MW [349]. Only a few data on the bactericidal activity of LMW chitosan could be compared depending on bacteria 
tested, conditions of biological test and chitosan MW, but even in this case the results did not correspond to each other. Thus, chitosan of $9300 \mathrm{Da}$ restricted growth of E. coli, while chitosan of $2200 \mathrm{Da}$ promoted growth of this bacterium [350]. Increase in the MW led to a decrease in chitosan activity against $E$. coli in some studies [351, 352], while in the others an increased activity for a high MW (HMW) in comparison with LMW chitosan have been found [353]. In contrast to the above mentioned results, no differences in HMW and LMW chitosan activities were found against $E$. coli $[354,355]$ and Bacillus subtilis [351, 354].

It has been demonstrated that LMW chitosans (of less than $10 \mathrm{kDa}$ ) have greater antimicrobial activity than native chitosans. However, a DP of at least seven is required; lower MW fractions have little or no activity [227]. Chitosan with a MW ranging from 10,000 to $100,000 \mathrm{Da}$ would be helpful in restraining the growth of bacteria. In addition, chitosan with an average MW of $9300 \mathrm{Da}$ was effective against $E$. coli, while that with a MW of $2200 \mathrm{Da}$ accelerated growth of the same bacteria [356]. Tanigawa et al. [357] reported that D-glucosamine hydrochloride (chitosan monomer) did not show any growth inhibition against several bacteria, whereas chitosan was effective. This suggests that the antimicrobial activity of chitosan is related to not only its cationic nature but also to its chain length. Shimojoh et al. [358] also found that chitosan of 220,000 Da was most effective, whereas chitosan of 10,000 Da was the least effective in their bactericidal activities. However, the antimicrobial activity of chitosan of $70,000 \mathrm{Da}$ was better than of $426,000 \mathrm{Da}$ for some bacteria, but for the others, the effectiveness was reversed. Yalpani et al. [359] reported that medium MW chitosans showed higher antimicrobial activities against $B$. circulans than chitooligosaccharides (DP 2-30), whereas they were less effective against $E$. coli than chitooligosaccharides. From the results of Shimojoh et al. [358] and Yalpani et al. [359] one can notice that the relationship between MW of chitosan and the antimicrobial activity can be affected by the test organisms. Numerous researchers have reported that the antibacterial activity of chitosan is a MW dependant [291, 354, 357, 360, 361]. Hwang et al. [362] concluded that chitosan with MW bout 30,000 Da exhibited the highest bactericidal effect on $E$. coli from their investigation of MW range of 10,000-170,000 Da. Jeon et al. [354] suggested that the MW of chitosan is critical for the inhibition of microorganisms and suggested the required MW be higher than 10,000 Da for better antimicrobial activity.

The antimicrobial activity of different MWs chitosan and chitosan oligomers (DP 2-8) against several plant pathogens were examined by Hirano and Nagao [259]. It was observed that the increases in MW increased the number of inhibited fungi. The strongest growth inhibition was observed with LMW and the weakest was observed with HMW chitosan. Kendra and Hadwiger [223] examined the antifungal effect of chitosan oligomers on $F$. solani $f$. sp. pisi and F. solani f. sp. phaseoli. The antifungal activity was found to increase as the polymer size increased. Monomer and dimer units did not show any antifungal activity at $1000 \mu \mathrm{g} / \mathrm{mL}$. However, heptamer (DP = 7) showed maximal antifungal activity and the minimum concentrations were identical to those observed for both native chitosan and the acid-cleaved chitosan. We examined the antimicrobial activity of $3.60 \times 10^{5}, 6.11 \times 10^{5}$ and $9.53 \times 10^{5} \mathrm{Da}$ chitosans against plant pathogenic bacteria $A$. tumefaciens, C. fascians, E. amylovora, E. carotovora, P. solanacearum and S. lutea and fungi A. alternata, B. fabae, F. oxysporum, $P$. digitatum, $P$. debaryanum and $R$. solani. The results indicated that chitosans of $6.11 \times 10^{5}$ and $9.53 \times 10^{5} \mathrm{Da}$ were more potent in bactericidal activity than chitosan of $3.60 \times 10^{5} \mathrm{Da}$ and chitosan of $9.53 \times 10^{5} \mathrm{Da}$ exhibited a good antibacterial potency especially against $C$. fascians with MIC $500 \mathrm{mg} / \mathrm{L}$. The data demonstrated that the fungicidal activity was increased as MW increase and chitosan of 9.53 $\times 10^{5} \mathrm{Da}$ was the most potent one against all the tested fungi [250]. Recently we also investigated the antifungal activity of depolymerized chitosans $\left(0.5 \times 10^{4}, 3.7 \times 10^{4}, 5.7 \times 10^{4}\right.$, and $\left.2.9 \times 10^{5} \mathrm{Da}\right)$ on the gray mold caused by $B$. cinerea as in vitro and in vivo on tomato fruit [220]. In an in vitro experiment, the result demonstrated that the antifungal activity increased as the chitosan MW decreased. In an in vivo study, chitosan with $\mathrm{MW}$ of $5.7 \times 10^{4} \mathrm{Da}$ was the most effective among those tested.

It is difficult to find a clear correlation between MW and antimicrobial activity, generally the antimicrobial activity increases as the MW of chitosan increases. However, the activity decreases over a certain high MW. The discrepancies between data may result from the different DDA and MW distributions of chitosan. The evaluation of only the MW dependence of the antimicrobial activity requires a wide MW range of chitosan samples with the same DDA. It is almost impossible to obtain this because chitosan is a natural polymer. From the existing data, it is difficult to determine what the most optimal MW for the maximal antimicrobial activity is. The selection of MW of chitosan could be thought to be more dependent on its application.

7.2. Degree of Deacetylation. The antimicrobial activity of chitosan is directly proportional to the DDA of chitosan [291, $357,358,363]$. The increase in DDA means the increased number of amino groups on chitosan. As a result, chitosan has an increased number of protonated amino groups in an acidic condition and dissolves in water completely, which leads to an increased chance of interaction between chitosan and negatively charged cell walls of micro-organisms [224]. Variation of deacetylation process yielded chitosan with significant differences in DDA\% as well as variation of the MW. Simpson et al. [364] reported that chitosan with a DDA of $92.5 \%$ was more effective than chitosan with a DDA of $85 \%$. On the contrary, Ikinci et al. [365] reported that change in DDA (73, 84 and 95\%) did not have any effect on the antimicrobial activity of chitosan against Porphyromonas gingivalis.

Hongpattarakere and Riyaphan [366] prepared chitosan from black tiger shrimp carapace by deacetylation process performed in $50 \% \mathrm{NaOH}$ at $100^{\circ} \mathrm{C}$ under vacuum, nitrogen, and regular atmospheres. Each condition was maintained for $0.5,1$, and $2 \mathrm{~h}$. MIC values of chitosans varied depending on conditions of deacetylation processes, reaction times, and test micro-organisms. In general, chitosan prepared 
under atmosphere showed the lowest MIC value or highest inhibitory effect on test micro-organisms, whereas that deacetylated under nitrogen showed the least inhibitory effect. Chitosan obtained from $1 \mathrm{~h}$ of deacetylation under regular atmosphere showed the lowest MIC value (625 ppm) against E. coli and $S$. aureus, while Candida albicans was inhibited at MIC value of $312.5 \mathrm{ppm}$ due to its higher DDA and lower MW compared to chitosan deacetylated under vacuum and nitrogen atmospheres.

7.3. The $p H$. The antimicrobial activity of chitosan is strongly affected by the $\mathrm{pH}[226,243,244,291]$. Lower $\mathrm{pH}$ increases the antimicrobial activity for much the same reasons, in addition to the "hurdle effect" of inflicting acid stress on the target organisms. Tsai and Su [226] examined the antimicrobial activity of chitosan (DDA 0.98) against E. coli at different $\mathrm{pH}$ values of 5.0, 6.0, 7.0, 8.0, and 9.0. The greatest activity was observed at $\mathrm{pH}$ 5.0. The activity decreased as the $\mathrm{pH}$ increased and chitosan had little antibacterial activity at $\mathrm{pH} 9.0$. Other researchers [243, 291] reported that chitosan had no antimicrobial activity at $\mathrm{pH} 7.0$ due to the deprotonation of amino groups and poor solubility in water. This suggests that the antimicrobial activity comes from the cationic nature of chitosan.

7.4. Temperature. Temperature also has an effect on the antimicrobial activity of chitosan. Higher temperature $\left(37^{\circ} \mathrm{C}\right)$ has been shown to enhance its antimicrobial activity compared to refrigeration temperatures. However, the greatest single influence on antimicrobial activity is the surrounding matrix. Tsai and Su [226] examined the effect of temperature on the antibacterial activity of chitosan against E. coli. The cell suspensions in phosphate buffer ( $\mathrm{pH} 6.0$ ) containing 150 ppm chitosan were incubated at 4, 15, 25, and $37^{\circ} \mathrm{C}$ for various time intervals and the surviving cells were counted. The antibacterial activity was found to be directly proportional to the temperature. At the temperatures of 25 and $37^{\circ} \mathrm{C}$, the $\mathrm{E}$. coli cells were completely killed within 0.5 and $1 \mathrm{hr}$, respectively. However, at lower temperatures (4 and $15^{\circ} \mathrm{C}$ ) the number of $E$. coli declined within the first $5 \mathrm{hrs}$ and then stabilized. The authors concluded that the reduced antimicrobial activity resulted from the decreased rate of interaction between chitosan and cells at a lower temperature.

7.5. Cations and Polyanions. Young et al. [367] observed that chitosan-induced leakage of UV-absorbing material from Glycine max was strongly inhibited by divalent cations in the order of $\mathrm{Ba}^{+2}>\mathrm{Ca}^{+2}>\mathrm{Sr}^{+2}>\mathrm{Mg}^{+2}>\mathrm{Na}^{+}>$ $\mathrm{K}^{+}$. It was assumed that the cations displaced $\mathrm{Ca}^{+2}$ released from the cell surface, formed complexes stabilizing the cell membrane, and consequently reduced the chitosaninduced leakage. Young and Kauss [368] reported that chitosan caused the release of $\mathrm{Ca}^{+2}$ present on Glycine max cell and/or plasma membrane, which destabilized the cell membrane and further induces leakage of intracellular electrolytes. They suggested that the cross-linking of chitosan (polycation) with phospholipids or protein components in the cell membrane affects the membrane permeability, which further causes leakage of intracellular substances and finally causes the death of cell. Tsai and $\mathrm{Su}$ [226] also reported that reducing bactericidal effect of chitosan against $E$. coli by the addition of salts containing alkaline earth metals such as $\mathrm{MgCl}_{2}, \mathrm{BaCl}_{2}$, and $\mathrm{CaCl}_{2}$ was observed. The order of effectiveness was $\mathrm{Ba}^{+2}>\mathrm{Ca}^{+2}>\mathrm{Mg}^{+2}$. The authors proposed that the cations form complexes with chitosan and consequently the reduced available amino groups of chitosan led to the reduced bactericidal effect unlike Young's assumption [367]. In addition to the reduced chitosaninduced leakage by cations, the leakage was also reduced by the addition of polyanions such as sodium polygalacturonate and sodium poly-Laspartate. The complete prevention of electrolyte leakage was observed when the number of carboxyl groups in the polyanions was equal to that of the amino groups of chitosan. It was attributed to the formation of polycation (chitosan)-polyanion complexes, which were observed by formation of precipitate. However, monomeric galacturonate and aspartate did not show any effect on the leakage and no precipitation of chitosan was observed. The explanation of this provided by the authors was that individual ionic bonds between anionic monomers and polycations could dissociate, but the multiple bonds between polyanion and polycation would not dissociate at the same time.

\section{Mode of Antimicrobial Action of Chitosan}

Chitosan is a natural polymer and has no antigenic properties, and thus is perfectly compatible with living tissue. Its antithrombogenic and hemostatic properties make it very suitable for use in all fields of biology. The exact mechanisms of the antimicrobial activities of chitosan and its derivatives are still unknown. It is known that chitosan antimicrobial activity is influenced by a number of factors that act in an orderly and independent fashion. Because of the positive charge on the $\mathrm{C}-2$ of the glucosamine monomer below $\mathrm{pH}$ 6.0, chitosan is more soluble and has a better antimicrobial activity $[6,234]$. The polycationic structure forms unnecessarily in acidic conditions because the grafted groups of specific derivatives may change the $p K a$ of chitosan and cause protonation at higher $\mathrm{pH}$ value. When the positive charge density of chitosan strengthens, the antibacterial property will increase consequently, as is the case with quaternized chitosans $[70,109,369,370]$ and chitosan metal complexes $[145,148,371]$. On the contrary, if the polycationic property of chitosan is deprived or reversed, the corresponding antimicrobial capacity will be weakened or lost. Therefore, large amounts of amino groups are able to enhance the antimicrobial activity. Accordingly, native chitosan with higher DDA shows a stronger inhibitory effect than that a molecule with a lower DDA. Moreover, it has been reported that asparagine $N$-conjugated chitosan oligosaccharide that possesses two positively charged sites provides strong interaction with carboxyl-negative charges on the bacteria cell wall $[354,372]$.

Interaction between positively charged chitosan molecules and negatively charged microbial cell membranes leads to the leakage of proteinaceous and other intracellular 
constituents [6, 234, 241, 373-376]. Papineau et al. [239] and Sudarshan et al. [243] reported that chitosan acts mainly on the outer surface of the bacteria. At a lower concentration $(<200 \mathrm{mg} / \mathrm{L})$, the polycationic chitosan does probably bind to the negatively charged bacterial surface to cause agglutination, while at higher concentrations the larger number of positive charges may have imparted a net positive charge to the bacterial surfaces to keep them in suspension. Chitosan interacts with the membrane of the cell to alter cell permeability. For example, fermentation with baker's yeast is inhibited by certain cations, which act at the yeast cell surface to prevent the entry of glucose. UV-absorption studies indicated that chitosan caused considerable leakage of proteinaceous material from $P$. oaroecandrum at $\mathrm{pH} 5.8$ [377]. Chitosan also acts as a chelating agent that selectively binds trace metals and thereby inhibits the production of toxins and microbial growth $[274,275]$. It also activates several defense processes in the host tissue [215], acts as a water-binding agent, and inhibits various enzymes.

Another mechanism is that the positively charged chitosan interacts with cellular DNA of some fungi and bacteria, which consequently inhibits the RNA and protein synthesis $[243,378]$. In this mechanism, chitosan must be hydrolyzed to low MW to penetrate into the cell of micro-organisms however, this mechanism is still controversial. Tokura et al. [350] examined the antimicrobial action of chitosan with average MW of 2200 and $9300 \mathrm{Da}$ having DDA of 0.54 and 0.51 , respectively. It was observed that chitosan of $9300 \mathrm{Da}$ was stacked on the cell wall and inhibited the growth of E. coli. However, the chitosan of $2200 \mathrm{Da}$, which permeated into the cell wall, accelerated the growth of E. coli. They suggested that the antimicrobial action is related to the suppression of the metabolic activity of the bacteria by blocking nutrient permeation through the cell wall rather than the inhibition of the transcription from DNA. Chitosan also inhibits toxin production by $A$. alternata and macerating enzyme production by Erwinia in addition to eliciting phytoalexin production $[379,380]$. The effects of chitosan on growth inhibition of plant pathogenic fungi in fruits and vegetables were correlated with the reduction of aflatoxin, elicitation of phytoalexin and phenolic precursors, enhanced production of chitinases, and other factors relevant to the plant defenses [220, 381, 382]. El Ghaouth et al. [215, 216, 320] added that the fungistatic properties of chitosan against $R$. stolonifer were related to its ability to induce morphological changes in the cell wall. In addition to the direct effect of chitosan on different plant pathogens, it also activates several defense processes in treated plants or their products at postharvest stage. These defense mechanisms include accumulation of chitinases, synthesis of proteinase inhibitors, and lignification and induction of callous synthesis [320, 325]. For example, when applied on wounded wheat leaves, chitosan-induced lignifications, and consequently restricted the growth of nonpathogenic fungi in wheat. Chitosan inhibited the growth of $A$. flavus and aflatoxin production in liquid culture, preharvest maize, and groundnut, and it also enhanced phytoalexin production in germinating peanut [274, 275].
Unfortunately, in spite of the chitosan advantages, it is only soluble in acidic aqueous solutions with $\mathrm{pH}$ values lower than 6.5. At higher $\mathrm{pH}$ values, amino groups of chitosan macromolecules become unprotonated and chitosan forms insoluble. This problem is probably the major limiting factor for its utilization, that is, its application in biology, since many enzyme assays are performed at neutral $\mathrm{pH}$. If watersoluble chitosan would be easily accessible, it is expected that the biological and physiological potential of chitosan would increase dramatically. One of the strategies to increase both the solubility and positive charge density of chitosan macromolecule is based on the introduction of quaternary ammonium groups in chitosan. This modification has got the commonly accepted term "quaternization of chitosan". Thus, water-soluble chitosan derivatives soluble to both acidic and basic physiologic circumstances may be good candidates for the polycationic biocides [70, 383, 384]. The antimicrobial action of such compounds is believed to occur when the compounds are absorbed onto the bacterial cell surface, increasing the permeability of the lipid cell membrane and causing death through the loss of essential cell materials. In addition, these derivatives of chitosan are generally more active against gram-positive bacteria than their corresponding monomers. Antimicrobial activity generally increases as the content of the quaternary ammonium moiety increases. The antimicrobial activities of quaternary chitosan derivatives were evaluated against some of gram-positive, gram-negative bacteria, and fungi. It was found that the activity increased with increasing chain length of the alkyl substituent, and this was attributed to the contribution of the increased hydrophobic properties of the derivatives. These results clearly demonstrated that hydrophobicity and cationic charge of the introduced substituent strongly affect the antibacterial activity of quaternary chitosan derivatives [70, 110].

It can be concluded that the exact mechanism of the antimicrobial action of chitosan is still ambiguous, although six main mechanisms, none of which are mutually exclusive, have been proposed, as follows: (1) interactions between the positively charged moieties on the chitosan molecules and those negatively charged ones on the microbial cell outer membranes leads to changes in the cell membrane structure and permeability inducing the leakage of proteinaceous and other intracellular constituents and so challenging the biochemical and physiological competency of the bacteria leading to loss of replicative ability and eventual death; (2) chitosan acts as a chelating agent that selectively binds trace metals and subsequently inhibits the production of toxins and microbial growth; (3) chitosan activates several defense processes in the host tissue, acts as a water binding agent, and inhibits various enzymes; (4) LMW chitosan penetrates the cytosol of the micro-organisms and, through the binding of chitosan with DNA, results in the interference with the synthesis of mRNA and proteins; (5) Chitosan on the surface of the cell can form an impermeable polymeric layer which alters the cell permeability and prevents nutrients from entering the cell; (6) finally, since chitosan can adsorb the electronegative substances in the cell and flocculate them, it 
disturbs the physiological activities of the micro-organism leading to their death.

\section{Concluding Remarks}

The recourse to naturally occurring products with interesting antimicrobial and eliciting properties such as chitosan has been getting more attention in recent years. This product can be used in a number of ways to reduce plant disease levels and prevent the development and spread of pathogens, thus preserving crop yield and quality. The potent effect of chitosan on plant diseases control is from its antimicrobial properties and plant innate immunity elicited activity. The antimicrobial activity depend on several factors such as MW, DDA, solubility, positive charge density, chemical modification, $\mathrm{pH}$, concentration, hydrophilic/hydrophobic characteristic, chelating capacity, and type of micro-organism. Chitosan has also become a postharvest promising treatment for fruits and vegetables due to its natural character, antimicrobial activity, and elicitation of defense responses. It possesses filmforming and barrier properties, thus making it a potential raw material for edible films or coatings and can be used to improve the storability of perishable foods. In spite of the chitosan advantages, the poor solubility, low-surface area, and porosity of chitosan are the major limiting factors in its utilization. Therefore, several research groups have started to modify a chitosan molecule to produce high-antimicrobial active derivatives.

Though there are many papers focused on chitosan and its derivatives in plant protection, there are still many problems that need to be studied. Examination of better ways to incorporate these products into Integrated Pest Management strategies remains to be pursued in many major crops especially against plant pathogenic bacteria and fungi. Interesting theoretical and applied findings were gathered in recent years, whereas more are needed to examine the mechanisms governing the mode of action of these compounds when applied at large scales. In the case of antimicrobial mode of action, future work should aim at clarifying the molecular details of the underlying mechanisms and their relevance to the antimicrobial activity of chitosan. Moreover, further investigations in this area, in particular with regard to microorganism resistance mechanisms against this compound, are warranted. In addition, participation and collaboration of research institutes, industry, and government regulatory agencies will be the key for the success of the antimicrobial mechanism.

\section{References}

[1] J. E. Casida and G. B. Quistad, "Golden age of insecticide research: past, present, or future?" Annual Review of Entomology, vol. 43, pp. 1-16, 1998.

[2] R. L. Carson, Silent Spring, Riverside Press, Cambridge, Mass, USA, 1962.

[3] P. Houeto, G. Bindoula, and J. R. Hoffman, "Ethylenebisdithiocarbamates and ethylenethiourea: possible human health hazards," Environmental Health Perspectives, vol. 103, no. 6, pp. 568-573, 1995.
[4] S. Ben-Yeohshua and J. Mercier, "UV irradiation, biological agents, and natural compounds for controlling postharvest decay in fresh fruits and vegetables," in Environmentally Friendly Technologies for Agricultural Produce Quality, S. S. Ben-Yehoshua, Ed., pp. 266-299, Taylor \& Francis, Boca Raton, Fla, USA, 2005.

[5] A. El Ghaouth and C. L. Wilson, "Biologically-based technologies for the control of postharvest diseases," Postharvest News and Information, vol. 6, pp. 5N-11N, 1995.

[6] E. I. Rabea, M. E. T. Badawy, C. V. Stevens, G. Smagghe, and W. Steurbaut, "Chitosan as antimicrobial agent: applications and mode of action," Biomacromolecules, vol. 4, no. 6, pp. 1457-1465, 2003.

[7] R. A. A. Muzzarelli, "Chitin and its derivatives: new trends of applied research," Carbohydrate Polymers, vol. 3, no. 1, pp. 53-75, 1983.

[8] R. C. Goy, D. De Britto, and O. B. G. Assis, "A review of the antimicrobial activity of chitosan," Polimeros, vol. 19, no. 3, pp. 241-247, 2009.

[9] H. K. No and S. P. Meyers, "Preparation of chitin and chitosan," in Chitin Handbook, R. A. A. Muzzarelli and M. G. Peter, Eds., pp. 475-489, European Chitin Society, Grottammare, Italy, 1997.

[10] A. El Hadrami, L. R. Adam, I. El Hadrami, and F. Daayf, "Chitosan in plant protection," Marine Drugs, vol. 8, no. 4, pp. 968-987, 2010.

[11] H. Braconnot, "Sur la nature des champignons," Annual Chemistry, vol. 79, pp. 265-304, 1811.

[12] P. Labrude and C. Becq, "Pharmacist and chemist Henri BraconnotLe pharmacien et chimiste Henri Braconnot," Revue d"Histoire de la Pharmacie, vol. 51, no. 337, pp. 61-78, 2003.

[13] F. Hoppe-Seiler, "Ueber chitosan und zellulose," Berichte der Deutschen Chemischen Gesellschaft, vol. 27, pp. 3329-3331, 1894.

[14] P. Beaney, J. Lizardi-Mendoza, and M. Healy, "Comparison of chitins produced by chemical and bioprocessing methods," Journal of Chemical Technology and Biotechnology, vol. 80, no. 2, pp. 145-150, 2005.

[15] M. N. V. Ravi Kumar, "A review of chitin and chitosan applications," Reactive and Functional Polymers, vol. 46, no. 1, pp. 1-27, 2000.

[16] K. Kurita, "Chitin and chitosan: functional biopolymers from marine crustaceans," Marine Biotechnology, vol. 8, no. 3, pp. 203-226, 2006.

[17] G. McKay, H. S. Blair, and J. R. Gardner, "The adsorption of dyes onto chitin in fixed bed column and batch adsorbers," Journal of Applied Polymer Science, vol. 29, no. 5, pp. 14991514, 1984.

[18] K. M. Vårum, M. W. Anthonsen, H. Grasdalen, and O. Smidsrod, "Determination of the degree of $\mathrm{N}$-acetylation and the distribution of $N$-acetyl groups in partially $N$ deacetylated chitins (chitosans) by high-field N.M.R. spectroscopy," Carbohydrate Research, vol. 211, no. 1, pp. 17-23, 1991.

[19] H. K. No and S. P. Meyers, "Preparation of chitin and chitosan," in Chitin Handbook, R. A. A. Muzzarelli and M. G. Peter, Eds., pp. 475-489, European Chitin Society, Grottammare, Italy, 1997.

[20] S. Hirano, "Chitin biotechnology applications," Biotechnology Annual Review, vol. 2, pp. 237-258, 1996. 
[21] Y. Shigemasa and S. Minami, "Applications of chitin and chitosan for biomaterials," Biotechnology and Genetic Engineering Reviews, vol. 13, pp. 413-420, 1996.

[22] F. Shahidi, J. K. V. Arachchi, and Y. J. Jeon, "Food applications of chitin and chitosans," Trends in Food Science and Technology, vol. 10, no. 2, pp. 37-51, 1999.

[23] R. A. A. Muzzarelli, "Filmogenic properties of chitin/chitosan," in Chitin in Nature and Technology, R. C. Muzzarelli and G. W. Jeuniaux, Eds., pp. 389-396, Plenum Press, New York, NY, USA, 1986.

[24] P. A. Sandford, "Commercial sources of chitin and chitosan and their utilization," in Advances in Chitin Sciences, K. M. Vårum, A. Domard, and O. Smidsrød, Eds., vol. 6, p. 35, NTNU Trondheim, Trondheim, Norway, 2003.

[25] C. Jeuniaux and M. F. Voss-Foucart, "Chitin biomass and production in the marine environment," Biochemical Systematics and Ecology, vol. 19, no. 5, pp. 347-356, 1991.

[26] G. A. F. Roberts, Chitin Chemistry, Macmillan, Indianapolis, Ind, USA, 1992.

[27] J. Synowiecki and N. A. A. Q. Al-Khateeb, "Mycelia of Mucor rouxii as a source of chitin and chitosan," Food Chemistry, vol. 60, no. 4, pp. 605-610, 1997.

[28] P. A. Sandford, "Chitosan-commercial uses and potential applications," in Chitin and Chitosan, G. S. Brack, T. Anthonsen, and P. Sandford, Eds., pp. 51-69, Elsevier, New York, NY, USA, 1989.

[29] D. Horton and D. R. Lineback, "N-deacetylation, chitosan from chitin," in Methods in Carbohydrate Chemistry, R. L. Whistler and M. L. Wolfson, Eds., p. 403, Academic Press, New York, NY, USA, 1965.

[30] W. A. Bough, W. L. Salter, A. C. M. Wu, and B. E. Perkins, "Influence of manufacturing variables on the characteristics and effectiveness of chitosan products. I. Chemical composition, viscosity, and molecular-weight distribution of chitosan products," Biotechnology and Bioengineering, vol. 20, no. 12, pp. 1931-1943, 1978.

[31] H. K. No, K. S. Lee, and S. P. Meyers, "Correlation between physicochemical characteristics and binding capacities of chitosan products," Journal of Food Science, vol. 65, no. 7, pp. 1134-1137, 2000.

[32] P. L. Dung, M. Milas, M. Rinaudo, and J. Desbrières, "Water soluble derivatives obtained by controlled chemical modifications of chitosan," Carbohydrate Polymers, vol. 24, no. 3, pp. 209-214, 1994.

[33] V. Sousa Andrade, B. De Barros Neto, K. Fukushima, and G. M. De Campos-Takaki, "Effect of medium components and time of cultivation on chitin production by Mucor circinelloides (Mucor javanicus IFO 4570)—a factorial study," Revista Iberoamericana de Micologia, vol. 20, no. 4, pp. 149153, 2003.

[34] T. Chandy and C. P. Sharma, "Chitosan-as a biomaterial," Biomaterials, Artificial Cells, and Artificial Organs, vol. 18, no. 1, pp. 1-24, 1990.

[35] E. P. Feofilova, D. V. Nemtsev, V. M. Tereshina, and V. P. Kozlov, "Polyaminosaccharides of mycelial fungi: new biotechnological use and practical implications (review)," Applied Biochemistry and Microbiology, vol. 32, no. 5, pp. 437-445, 1996.

[36] KE. J. Hu, J. L. Hu, K. P. Ho, and K. W. Yeung, "Screening of fungi for chitosan producers, and copper adsorption capacity of fungal chitosan and chitosanaceous materials," Carbohydrate Polymers, vol. 58, no. 1, pp. 45-52, 2004.
[37] M. Rinaudo, P. Le Dung, C. Gey, and M. Milas, "Substituent distribution on $\mathrm{O}, \mathrm{N}$-carboxymethylchitosans by ${ }^{1} \mathrm{H}$ and ${ }^{13} \mathrm{C}$ N.M.R," International Journal of Biological Macromolecules, vol. 14, no. 3, pp. 122-128, 1992.

[38] S. V. Nemtsev, O. Y. Zueva, M. R. Khismatullin, A. I. Albulov, and V. P. Varlamov, "Isolation of chitin and chitosan from honeybees," Applied Biochemistry and Microbiology, vol. 40, no. 1, pp. 39-43, 2004.

[39] P. Pochanavanich and W. Suntornsuk, "Fungal chitosan production and its characterization," Letters in Applied Microbiology, vol. 35, no. 1, pp. 17-21, 2002.

[40] J. Synowiecki and N. A. Al-Khateeb, "Production, properties, and some new applications of chitin and its derivatives," Critical Reviews in Food Science and Nutrition, vol. 43, no. 2, pp. 145-171, 2003.

[41] S. C. Tan, T. K. Tan, S. M. Wong, and E. Khor, "The chitosan yield of zygomycetes at their optimum harvesting time," Carbohydrate Polymers, vol. 30, no. 4, pp. 239-242, 1996.

[42] W. L. Teng, E. Khor, T. K. Tan, L. Y. Lim, and S. C. Tan, "Concurrent production of chitin from shrimp shells and fungi," Carbohydrate Research, vol. 332, no. 3, pp. 305-316, 2001.

[43] V. S. Andrade, B. B. Neto, W. Souza, and G. M. CamposTakaki, "A factorial design analysis of chitin production by Cunninghamella elegans," Canadian Journal of Microbiology, vol. 46, no. 11, pp. 1042-1045, 2000.

[44] G. M. Campos-Takaki, "The fungal versatility on the copolymers chitin and chitosan production," in Chitin and Chitosan Opportunities and Challenges, P. K. Dutta, Ed., pp. 69-94, SSM: International Publication, Midnapore, India, 2005.

[45] R. V. S. Amorim, W. M. Ledingham, K. Fukushima, and G. M. Campos-Takaki, "Screening of chitin deacetylase from Mucoralean strains (Zygomycetes) and its relationship to cell growth rate," Journal of Industrial Microbiology and Biotechnology, vol. 32, no. 1, pp. 19-23, 2005.

[46] S. Benjakul and P. Sophanodora, "Chitosan production from carapace and shell of black tiger shrimp," ASEAN Food Journal, vol. 8, pp. 145-148, 1993.

[47] K. Nadarajah, J. Kader, M. Mazmira, and D. C. Paul, "Production of chitosan by fungi," Pakistan Journal of Biological Science, vol. 4, pp. 263-265, 2001.

[48] T. C. M. Stamford, T. L. M. Stamford, N. P. Stamford, B. D. B. Neto, and G. M. De Campos-Takaki, "Growth of Cunninghamella elegans UCP 542 and production of chitin and chitosan using yam bean medium," Electronic Journal of Biotechnology, vol. 10, no. 1, pp. 61-68, 2007.

[49] F. Di Mario, P. Rapanà, U. Tomati, and E. Galli, "Chitin and chitosan from Basidiomycetes," International Journal of Biological Macromolecules, vol. 43, no. 1, pp. 8-12, 2008.

[50] C. Crestini, B. Kovac, and G. Giovannozzi-Sermanni, "Production and isolation of chitosan by submerged and solidstate fermentation from Lentinus edodes," Biotechnology and Bioengineering, vol. 50, no. 2, pp. 207-210, 1996.

[51] U. Carlberg, "Chitin contents of different development stages of stick insects (Phasmida)," Zoologische Jahrbuecher, Abteilung fuer Allgemeine Zoologie und Physiologie der Tiere, vol. 86, p. 413, 1982.

[52] A. T. Paulino, J. I. Simionato, J. C. Garcia, and J. Nozaki, "Characterization of chitosan and chitin produced from silkworm crysalides," Carbohydrate Polymers, vol. 64, no. 1, pp. 98-103, 2006. 
[53] O. E. Tauber, "The distribution of chitin in an insect," Journal of Morphology, vol. 56, pp. 51-58, 2005.

[54] P. Veronico, L. J. Gray, J. T. Jones et al., "Nematode chitin synthases: gene structure, expression and function in Caenorhabditis elegans and the plant parasitic nematode Meloidogyne artiellia," Molecular Genetics and Genomics, vol. 266, no. 1, pp. 28-34, 2001.

[55] A. Haga, "Preparation of chitin from thin-shelled cocoons with pupa obtained as waste from the silk reeling process," in Proceedings of the 2nd Asia Pacific Chitin and Chitosan Symposium, Bangkok, Thailand, 1996.

[56] K. Ogawa and T. Yui, "Structure and function of chitosan. 3. Crystallinity of partially $N$-acetylated chitosans," Bioscience, Biotechnology and Biochemistry, vol. 57, pp. 1466-1469, 1993.

[57] K. V. Harish Prashanth, F. S. Kittur, and R. N. Tharanathan, "Solid state structure of chitosan prepared under different $N$ deacetylating conditions," Carbohydrate Polymers, vol. 50, no. 1, pp. 27-33, 2002.

[58] M. Jaworska, K. Sakurai, P. Gaudon, and E. Guibal, "Influence of chitosan characteristics on polymer properties. I: crystallographic properties," Polymer International, vol. 52, no. 2, pp. 198-205, 2003.

[59] D. K. Rout, S. K. Pulapura, and R. A. Gross, "Liquid crystalline characteristics of site-selectively-modified chitosan," Macromolecules, vol. 26, no. 22, pp. 5999-6006, 1993.

[60] A. Baxter, M. Dillon, K. D. A. Taylor, and G. A. F. Roberts, "Improved method for a determination of the degree of $\mathrm{N}$ acetylation of chitosan," International Journal of Biological Macromolecules, vol. 14, no. 3, pp. 166-169, 1992.

[61] A. Domard, "pH and CD measurements on a fully deacetylated chitosan: application to $\mathrm{Cu}(\mathrm{II})$-polymer interactions," International Journal of Biological Macromolecules, vol. 9, no. 2, pp. 98-104, 1987.

[62] M. L. Duarte, M. C. Ferreira, M. R. Marvão, and J. Rocha, "An optimised method to determine the degree of acetylation of chitin and chitosan by FTIR spectroscopy," International Journal of Biological Macromolecules, vol. 31, no. 1-3, pp. 18, 2002.

[63] T. D. Rathke and S. M. Hodson, "Review of chitin and chitosan as fibre and film formers," Journal of Molecular Science. Reviews in Macromolecular Chemistry, vol. C34, p. 375, 1994.

[64] L. Raymond, F. G. Morin, and R. H. Marchessault, "Degree of deacetylation of chitosan using conductometric titration and solid-state NMR," Carbohydrate Research, vol. 246, pp. 331-336, 1993.

[65] H. Sashiwa, H. Saimoto, Y. Shigemasa, and S. Tokura, "Nacetyl group distribution in partially deacetylated chitins prepared under homogeneous conditions," Carbohydrate Research, vol. 242, pp. 167-172, 1993.

[66] A. Ebert and H. P. Fink, "Solid state NMR spectroscopy of chitin and chitosan," in Chitin Handbook, R. A. A. Muzzarelli and M. G. Peter, Eds., p. 137, European Chitin Society, Grottammare, Italy, 1997.

[67] Y. Inoue, "NMR determination of the degree of acetylation," in Chitin Handbook, R. A. A. Muzzarelli and M. G. Peter, Eds., pp. 133-136, European Chitin Society, Grottammare, Italy, 1997.

[68] R. A. A. Muzzarelli, R. Rocchetti, V. Stanic, and M. Weckx, "Methods for the determination of the degree of acetylation of chitin and chitosan," in Chitin Handbook, R. A. A. Muzzarelli and M. G. Peter, Eds., pp. 109-119, European Chitin Society, Grottammare, Italy, 1997.
[69] G. A. F. Roberts, "Determination of the degree of $N$ acetylation of chitin and chitosan," in Chitin Handbook, R. A. A. Muzzarelli and M. G. Peter, Eds., pp. 127-132, European Chitin Society, Grottammare, Italy, 1997.

[70] M. E. I. Badawy, "Structure and antimicrobial activity relationship of quaternary $N$-alkyl chitosan derivatives against some plant pathogens," Journal of Applied Polymer Science, vol. 117, no. 2, pp. 960-969, 2010.

[71] M. E. I. Badawy, E. I. Rabea, T. M. Rogge et al., "Synthesis and fungicidal activity of new $\mathrm{N}, \mathrm{O}$-acyl chitosan derivatives," Biomacromolecules, vol. 5, no. 2, pp. 589-595, 2004.

[72] M. R. Kasaai, "Determination of the degree of $N$-acetylation for chitin and chitosan by various NMR spectroscopy techniques: a review," Carbohydrate Polymers, vol. 79, no. 4, pp. 801-810, 2010.

[73] F. Lebouc, I. Dez, and P. J. Madec, "NMR study of the phosphonomethylation reaction on chitosan," Polymer, vol. 46, no. 2, pp. 319-325, 2005.

[74] A. Hirai, H. Odani, and A. Nakajima, "Determination of degree of deacetylation of chitosan by ${ }^{1} \mathrm{H}$ NMR spectroscopy," Polymer Bulletin, vol. 26, no. 1, pp. 87-94, 1991.

[75] H. Sashiwa and Y. Shigemasa, "Chemical modification of chitin and chitosan. 2: preparation and water soluble property of $N$-acylated or $N$-alkylated partially deacetylated chitins," Carbohydrate Polymers, vol. 39, no. 2, pp. 127-138, 1999.

[76] M. El Badawy, "Chemical modification of chitosan: synthesis and biological activity of new heterocyclic chitosan derivatives," Polymer International, vol. 57, no. 2, pp. 254-261, 2008.

[77] M. E. I. Badawy, E. I. Rabea, T. M. Rogge et al., "Fungicidal and insecticidal activity of $\mathrm{O}$-acyl chitosan derivatives," Polymer Bulletin, vol. 54, no. 4-5, pp. 279-289, 2005.

[78] E. I. Rabea, M. E. I. Badawy, W. Steurbaut, and C. V. Stevens, "In vitro assessment of $\mathrm{N}$-(benzyl)chitosan derivatives against some plant pathogenic bacteria and fungi," European Polymer Journal, vol. 45, no. 1, pp. 237-245, 2009.

[79] H. Sashiwa, N. Kawasaki, A. Nakayama et al., "Chemical modification of chitosan. 13. Synthesis of organosoluble, palladium adsorbable, and biodegradable chitosan derivatives toward the chemical plating on plastics," Biomacromolecules, vol. 3, no. 5, pp. 1120-1125, 2002.

[80] W. Kuhn and H. Kuhn, "Die Frage nach der Aufrollung von Fadenmolekülen in strömenden Lösungen," Helvetica Chimica Acta, vol. 26, pp. 1394-1465, 1943.

[81] H. Mark, Der feste Körper, Hirzel, Leipzig, Germany, 1938.

[82] W. Wang, S. Bo, S. Li, and W. Qin, "Determination of the Mark-Houwink equation for chitosans with different degrees of deacetylation," International Journal of Biological Macromolecules, vol. 13, no. 5, pp. 281-285, 1991.

[83] G. Berth and H. Dautzenberg, "The degree of acetylation of chitosans and its effect on the chain conformation in aqueous solution," Carbohydrate Polymers, vol. 47, no. 1, pp. 39-51, 2002.

[84] M. W. Anthonsen, K. M. Vårum, and O. Smidsrød, "Solution properties of chitosans: conformation and chain stiffness of chitosans with different degrees of $N$-acetylation," Carbohydrate Polymers, vol. 22, no. 3, pp. 193-201, 1993.

[85] M. Rinaudo, "Properties and degradation of selected polysaccharides: hyaluronan and chitosan," Corrosion Engineering Science and Technology, vol. 42, no. 4, pp. 324-334, 2007.

[86] J. Brugnerotto, J. Desbrières, G. Roberts, and M. Rinaudo, "Characterization of chitosan by steric exclusion chromatography,” Polymer, vol. 42, no. 25, pp. 9921-9927, 2001. 
[87] M. Bohdanecky and J. Kovar, Viscosity of Polymer Solutions, Elsevier, Amsterdam, The Netherlands, 1982.

[88] W. W. Yau, J. J. Kirkland, and D. D. Bly, Modern Size Exclusion Liquid Chromatography, John Wiley and Sons, New York, NY, USA, 1979.

[89] G. G. Allan and M. Peyron, "Molecular weight manipulation of chitosan I: kinetics of depolymerization by nitrous acid," Carbohydrate Research, vol. 277, no. 2, pp. 257-272, 1995.

[90] G. G. Allan and M. Peyron, "Molecular weight manipulation of chitosan II: prediction and control of extent of depolymerization by nitrous acid," Carbohydrate Research, vol. 277, no. 2, pp. 273-282, 1995.

[91] M. Rinaudo and A. Domard, "Solution properties of chitosan," in Chitin and Chitosan, G. Skjåk-Bræk, T. Anthonsen, and P. Sandford, Eds., pp. 71-86, Elsevier, London, UK, 1989.

[92] P. J. Flory, Principles of Polymer Chemistry, Cornell University Press, Ithaca, NY, USA, 1953.

[93] C. Tanford, Physical Chemistry of Macromolecules, John Wiley Press, New York, NY, USA, 1961.

[94] M. Terbojevich and A. Cosani, "Molecular weight determination of chitin and chitosan," in Chitin Handbook Atec, R. A. A. Muzzarelli and M. G. Peter, Eds., pp. 87-101, Grottammare, Italy, 1997.

[95] M. Huglin, Light Scattering from Polymer Solutions, Academic Press, New York, NY, USA, 1972.

[96] R. A. A. Muzzarelli, C. Lough, and M. Emanuelli, "The molecular weight of chitosans studied by laser lightscattering," Carbohydrate Research, vol. 164, pp. 433-442, 1987.

[97] C. Schatz, C. Pichot, T. Delair, C. Viton, and A. Domard, "Static light scattering studies on chitosan solutions: from macromolecular chains to colloidal dispersions," Langmuir, vol. 19, no. 23, pp. 9896-9903, 2003.

[98] A. Hugerth, N. Caram-Lelham, and L. O. Sundelöf, "The effect of charge density and conformation on the polyelectrolyte complex formation between carrageenan and chitosan," Carbohydrate Polymers, vol. 34, no. 3, pp. 149-156, 1997.

[99] T. Sannan, K. Kurita, and Y. Iwakura, "Studies on chitin, 2. Effect of deacetylation on solubility," Die Makromolekulare Chemie, vol. 177, pp. 3589-3600, 1976.

[100] M. Rinaudo, G. Pavlov, and J. Desbrières, "Influence of acetic acid concentration on the solubilization of chitosan," Polymer, vol. 40, no. 25, pp. 7029-7032, 1999.

[101] P. Gross, E. Konrad, and H. Mager, "Investigations on chitosan as a natural film forming ingredient in hair cosmetic products under the consideration of ecological aspects," Parfuem Kosmet, vol. 64, p. 367, 1983.

[102] P. Sorlier, A. Denuzière, C. Viton, and A. Domard, "Relation between the degree of acetylation and the electrostatic properties of chitin and chitosan," Biomacromolecules, vol. 2, no. 3, pp. 765-772, 2001.

[103] S. P. Strand, T. Tømmeraas, K. M. Vårum, and K. Østgaard, "Electrophoretic light scattering studies of chitosans with different degrees of $\mathrm{N}$-acetylation," Biomacromolecules, vol. 2, no. 4, pp. 1310-1314, 2001.

[104] S. M. Hudson and D. W. Jenkins, Chitin and Chitosan, Encyclopedia of Polymer Science and Technology, Wiley Interscience, New York, NY, USA, 3rd edition, 2001.

[105] S. Fujii, H. Kumagai, and M. Noda, "Preparation of poly(acyl)chitosans,” Carbohydrate Research, vol. 83, pp. 389393, 1980.
[106] K. Kurita, M. Kobayashi, T. Munakata, S. Ishii, and S. I. Nishimura, "Synthesis of non-natural branched polysaccharides. Regioselective introduction of $\alpha$-mannoside branches into chitin," Chemistry Letters, vol. 23, p. 2063, 1994.

[107] J. Holappa, T. Nevalainen, J. Savolainen et al., "Synthesis and characterization of chitosan $\mathrm{N}$-betainates having various degrees of substitution," Macromolecules, vol. 37, no. 8, pp. 2784-2789, 2004.

[108] S. I. Nishimura, O. Kohgo, K. Kurita, and H. Kuzuhara, "Chemospecific manipulations of a rigid polysaccharide: syntheses of novel chitosan derivatives with excellent solubility in common organic solvents by regioselective chemical modifications," Macromolecules, vol. 24, no. 17, pp. 47454748, 1991.

[109] Z. Jia, D. Shen, and W. Xu, "Synthesis and antibacterial activities of quaternary ammonium salt of chitosan," Carbohydrate Research, vol. 333, no. 1, pp. 1-6, 2001.

[110] C. H. Kim and K. S. Choi, "Synthesis and antibacterial activity of quaternized chitosan derivatives having different methylene spacers," Journal of Industrial and Engineering Chemistry, vol. 8, no. 1, pp. 71-76, 2002.

[111] M. Rinaudo, "Chitin and chitosan: properties and applications," Progress in Polymer Science, vol. 31, no. 7, pp. 603-632, 2006.

[112] W. Jiang and S. Han, "Sensibility of the chitosan to the addition of salt by viscometry," Acta Polymerica Sinica, no. 5, pp. 571-572, 1998.

[113] D. G. Rao, "Studies on viscosity-molecular weight relationship of chitosan solutions," Journal of Food Science and Technology, vol. 30, pp. 66-67, 1993.

[114] S. I. Aiba, "Studies on chitosan: 2. Solution stability and reactivity of partially $N$-acetylated chitosan derivatives in aqueous media," International Journal of Biological Macromolecules, vol. 11, no. 4, pp. 249-252, 1989.

[115] S. Hirano and T. Moriyasu, "N-(carboxyacyl)chitosans," Carbohydrate Research, vol. 92, no. 2, pp. 323-327, 1981.

[116] S. Hirano and T. Moriyasu, "Some novel $N$ (carboxyacyl)chitosan filaments," Carbohydrate Polymers, vol. 55, no. 3, pp. 245-248, 2004.

[117] S. Hirano, Y. Yamaguchi, and M. Kamiya, "Water-soluble $N$-(n-fatty acyl)chitosans," Macromolecular Bioscience, vol. 3, no. 10, pp. 629-631, 2003.

[118] R. A. A. Muzzarelli, Chitin, in the Polysaccharides, Vol. 3, G. O. Aspinall, Ed., Academic Press, New York, NY, USA, 1985.

[119] E. I. Rabea, M. E. I. Badawy, T. M. Rogge et al., "Insecticidal and fungicidal activity of new synthesized chitosan derivatives," Pest Management Science, vol. 61, no. 10, pp. 951-960, 2005.

[120] E. I. Rabea, M. E. I. Badawy, T. M. Rogge et al., "Enhancement of fungicidal and insecticidal activity by reductive alkylation of chitosan," Pest Management Science, vol. 62, no. 9, pp. 890897, 2006.

[121] T. P. Labuza and W. M. Breene, "Applications of active packaging for improvement of shelf-life and nutritional quality of fresh and extended shelf-life foods," Journal of Food Processing and Preservation, vol. 13, p. 1, 1989.

[122] S. Roller, "The antimicrobial action of chitosan: laboratory curiosity or novel food preservative?" in Advances in Chitin Sciences, K. M. Vårum, A. Domard, and O. Smidsrød, Eds., vol. 6, p. 43, NTNU Trondheim, Trondheim, Norway, 2003.

[123] J. Hosokawa, M. Nishiyama, K. Yoshihara, T. Kubo, and A. Terabe, "Reaction between chitosan and cellulose on biodegradable composite film formation," Industrial \& Engineering Chemistry Research, vol. 30, no. 4, pp. 788-792, 1991. 
[124] T. Uragami, "Preparation and characteristics of chitosan membranes," in Chitin Handbook, R. A. A. Muzzarelli and M. G. Peter, Eds., p. 451, European Chitin Society, Grottammare, Italy, 1997.

[125] P. D. Hoagland and N. Parris, "Chitosan/pectin laminated films," Journal of Agricultural and Food Chemistry, vol. 44, no. 7, pp. 1915-1919, 1996.

[126] J. Hosokawa, M. Nishiyama, K. Yoshihara, and T. Kubo, "Biodegradable film derived from chitosan and homogenized cellulose," Industrials and Engineering Chemistry Research, vol. 29, no. 5, pp. 800-805, 1990.

[127] D. W. S. Wong, F. A. Gastineau, K. S. Gregorski, S. J. Tillin, and A. E. Pavlath, "Chitosan-lipid films: microstructure and surface energy," Journal of Agricultural and Food Chemistry, vol. 40, no. 4, pp. 540-544, 1992.

[128] Q. Wu and L. Zhang, "Structure and properties of casting films blended with starch and waterborne polyurethane," Journal of Applied Polymer Science, vol. 79, no. 11, pp. 20062013, 2001.

[129] Y. X. Xu, K. M. Kim, M. A. Hanna, and D. Nag, "Chitosanstarch composite film: preparation and characterization," Industrial Crops and Products, vol. 21, no. 2, pp. 185-192, 2005.

[130] E. R. Hayes and D. H. Davies, "Characterization of chitosan. I. Thermoreversible chitosan gels," in Proceedings of the 1st International Conference on Chitin and Chitosan, p. 193, 1978.

[131] S. Hirano, S. Kondo, and Y. Ohe, "Chitosan gel: a novel polysaccharide gel,” Polymer, vol. 16, no. 8, p. 622, 1975.

[132] S. Hirano, R. Yamaguchi, N. Fukui, and M. Iwata, "A chitosan oxalate gel: its conversion to an $\mathrm{N}$-acetylchitosan gel via a chitosan gel," Carbohydrate Research, vol. 201, no. 1, pp. 145149,1990 .

[133] T. Gotoh, K. Matsushima, and K. I. Kikuchi, "Preparation of alginate-chitosan hybrid gel beads and adsorption of divalent metal ions," Chemosphere, vol. 55, no. 1, pp. 135-140, 2004.

[134] K. I. Draget, K. M. Vårum, E. Moen, H. Gynnild, and O. Smidsrod, "Chitosan cross-linked with Mo(VI) polyoxyanions: a new gelling system," Biomaterials, vol. 13, no. 9, pp. 635-638, 1992.

[135] K. I. Draget, "Associating phenomena in highly acetylated chitosan gels," Polymer Gels and Networks, vol. 4, no. 2, pp. 143-151, 1996.

[136] G. A. F. Roberts and K. E. Taylor, "Chitosan gels. 3. The formation of gels by reaction of chitosan with glutaraldehyde," Die Makromolekulare Chemie, vol. 190, p. 951, 1989.

[137] T. Chen, R. Vazquez-Duhalt, C. F. Wu, W. E. Bentley, and G. F. Payne, "Combinatorial screening for enzyme-mediated coupling. Tyrosinase-catalyzed coupling to create proteinchitosan conjugates," Biomacromolecules, vol. 2, no. 2, pp. 456-462, 2001.

[138] B. Krajewska, "Application of chitin- and chitosan-based materials for enzyme immobilizations: a review," Enzyme and Microbial Technology, vol. 35, no. 2-3, pp. 126-139, 2004.

[139] G. Kumar, J. F. Bristow, P. J. Smith, and G. F. Payne, "Enzymatic gelation of the natural polymer chitosan," Polymer, vol. 41, no. 6, pp. 2157-2168, 2000.

[140] A. J. Varma, S. V. Deshpande, and J. F. Kennedy, "Metal complexation by chitosan and its derivatives: a review," Carbohydrate Polymers, vol. 55, no. 1, pp. 77-93, 2004.

[141] S. S. Koide, "Chitin-chitosan: properties, benefits and risks," Nutrition Research, vol. 18, no. 6, pp. 1091-1101, 1998.

[142] D. J. Ormrod, C. C. Holmes, and T. E. Miller, "Dietary chitosan inhibits hypercholesterolaemia and atherogenesis in the apolipoprotein E-deficient mouse model of atherosclerosis," Atherosclerosis, vol. 138, no. 2, pp. 329-334, 1998.

[143] M. Rhazi, J. Desbrières, A. Tolaimate, M. Rinaudo, P. Vottero, and A. Alagui, "Contribution to the study of the complexation of copper by chitosan and oligomers," Polymer, vol. 43, no. 4, pp. 1267-1276, 2002.

[144] I. M. N. Vold, K. M. Vårum, E. Guibal, and O. Smidsrød, "Binding of ions to chitosan-selectivity studies," Carbohydrate Polymers, vol. 54, no. 4, pp. 471-477, 2003.

[145] M. E. I. Badawy, "Preparation and antimicrobial activity of some chitosan-metal complexes against some plant pathogenic bacteria and fungi," Journal of Pest Control and Environmental Sciences, vol. 18, pp. 37-50, 2010.

[146] A. Higazy, M. Hashem, A. ElShafei, N. Shaker, and M. A. Hady, "Development of antimicrobial jute packaging using chitosan and chitosan-metal complex," Carbohydrate Polymers, vol. 79, no. 4, pp. 867-874, 2010.

[147] S. Mekahlia and B. Bouzid, "Chitosan-Copper (II) complex as antibacterial agent: synthesis, characterization and coordinating bond-activity correlation study," Physics Procedia, vol. 2, no. 3, pp. 1045-1053, 2009.

[148] X. Wang, Y. Du, and H. Liu, "Preparation, characterization and antimicrobial activity of chitosan-Zn complex," Carbohydrate Polymers, vol. 56, no. 1, pp. 21-26, 2004.

[149] X. Wang, Y. Du, L. Fan, H. Liu, and Y. Hu, "Chitosan- metal complexes as antimicrobial agent: synthesis, characterization and Structure-activity study," Polymer Bulletin, vol. 55, no. 1-2, pp. 105-113, 2005.

[150] Y. I. Cho, H. K. No, and S. P. Meyers, "Physicochemical characteristics and functional properties of various commercial chitin and chitosan products," Journal of Agricultural and Food Chemistry, vol. 46, no. 9, pp. 3839-3843, 1998.

[151] L. F. Del Blanco, M. S. Rodriguez, P. C. Schulz, and E. Agulló, "Influence of the deacetylation degree on chitosan emulsification properties," Colloid and Polymer Science, vol. 277, no. 11, pp. 1087-1092, 1999.

[152] S. K. Rout, Physicochemical, functional, and spectroscopic analysis of crawfish chitin and chitosan as affected by process modification, dissertation, Louisiana State University, Baton Rouge, La, USA, 2001.

[153] L. D. Hall and M. Yalpani, "Formation of branched-chain, soluble polysaccharides from chitosan," Journal of the Chemical Society, Chemical Communications, no. 23, pp. 1153-1154, 1980.

[154] M. Yalpani and L. D. Hall, "Some chemical and analytical aspects of polysaccharide modifications. 3. Formation of branched-chain, soluble chitosan derivatives," Macromolecules, vol. 17, no. 3, pp. 272-281, 1984.

[155] S. M. Hudson and D. W. Jenkins, "Chitin and hitosan," in EPST, H. F. Mark, Ed., vol. 1, pp. 569-580, Wiley, New York, NY, USA, 3rd edition, 2003.

[156] M. Morimoto, H. Saimoto, and Y. Shigemasa, "Control of functions of chitin and chitosan by chemical modification," Trends in Glycoscience and Glycotechnology, vol. 14, no. 78, pp. 205-222, 2002.

[157] R. A. A. Muzzarelli and F. Tanfani, "The N-permethylation of chitosan and the preparation of $N$-trimethyl chitosan iodide," Carbohydrate Polymers, vol. 5, no. 4, pp. 297-307, 1985.

[158] M. Rinaudo and J. Reguant, "Polysaccharide derivatives," in Natural Polymers and Agrofibres Composites, E. Frollini, A. Leao, and L. H. C. Mattoso, Eds., pp. 15-39, CIP-BRASIL, Sao Carlos, Brazil, 2000. 
[159] L. Illum, "Chitosan and its use as a pharmaceutical excipient," Pharmaceutical Research, vol. 15, no. 9, pp. 1326-1331, 1998.

[160] C. Mireles, M. Martino, J. Bouzas, and J. A. Torres, "Complex formation of chitosan and naturally occurring polyanions," in Advances in Chitin and Chitosan, C. J. Brine, P. A. Sanford, and J. P. Zikakis, Eds., pp. 506-515, Elsevier, New York, NY, USA, 1992.

[161] C. A. Mireles-DeWitt, Complex mechanism of chitosan and naturally occurring polyanions, M.S. thesis, Oregon State University, Corvallis, Ore, USA, 1994.

[162] G. Lang, G. Maresch, and S. Birkel, "Hydroxyalkyl chitosans," in Chitin Handbook, R. A. A. Muzzarelli and M. G. Peter, Eds., pp. 61-66, European Chitin Society, Grottammare, Italy, 1997.

[163] G. Lang, G. Maresch, and H.-R. Lenz, "O-benzyl-Nhydroxyalkyl derivatives of chitosan and nail polish containing the same," U.S. Patent 4954619, 1990.

[164] J. Xu, S. P. McCarthy, R. A. Gross, and D. L. Kaplan, "Chitosan film acylation and effects on biodegradability," Macromolecules, vol. 29, no. 10, pp. 3436-3440, 1996.

[165] T. Satoh, L. Vladimirov, M. Johmen, and N. Sakairi, "Preparation and thermal dehydration of $N$-(carboxy)acyl chitosan derivatives with high stereoregularity," Chemistry Letters, vol. 32, no. 4, pp. 318-319, 2003.

[166] K. Kurita, Y. Koyama, S. Nishimura, and M. Kamiya, "Facile preparation of water-soluble chitin from chitosan," Chemistry Letters, vol. 9, pp. 1597-1598, 1989.

[167] K. Kurita, M. Kamiya, and S. I. Nishimura, "Solubilization of a rigid polysaccharide: controlled partial $\mathrm{N}$-acetylation of chitosan to develop solubility," Carbohydrate Polymers, vol. 16, no. 1, pp. 83-92, 1991.

[168] N. Kubota and Y. Eguchi, "Facile preparation of watersoluble $N$-acetylated chitosan and molecular weight dependence of its water-solubility," Polymer Journal, vol. 29, no. 2, pp. 123-127, 1997.

[169] O. Somorin, N. Nishi, H. Ohnuma, S. Tokura, and J. Noguchi, "Studies on chitin. 2. Preparation of benzyl and benzoylchitins," Polymer Journal, vol. 11, no. 5, pp. 391-396, 1979.

[170] K. Inui, K. Tsukamoto, T. Miyata, and T. Uragami, "Permeation and separation of a benzene/cyclohexane mixture through benzoylchitosan membranes," Journal of Membrane Science, vol. 138, no. 1, pp. 67-75, 1998.

[171] T. Uragami, K. Tsukamoto, K. Inui, and T. Miyata, "Pervaporation characteristics of a benzoylchitosan membrane for benzene-cyclohexane mixtures," Macromolecular Chemistry and Physics, vol. 199, no. 1, pp. 49-54, 1998.

[172] S. Hirano, Y. Yamaguchi, and M. Kamiya, "Novel Nsaturated-fatty-acyl derivatives of chitosan soluble in water and in aqueous acid and alkaline solutions," Carbohydrate Polymers, vol. 48, no. 2, pp. 203-207, 2002.

[173] M. Zhang and S. Hirano, "Novel $N$-unsaturated fatty acyl and $N$-trimethylacetyl derivatives of chitosan," Carbohydrate Polymers, vol. 26, no. 3, pp. 205-209, 1995.

[174] H. Sashiwa, N. Kawasaki, A. Nakayama, E. Muraki, N. Yamamoto, and S. I. Aiba, "Chemical modification of chitosan. 14: synthesis of water-soluble chitosan derivatives by simple acetylation," Biomacromolecules, vol. 3, no. 5, pp. 1126-1128, 2002.

[175] T. Seo, Y. Ikeda, K. Torada, Y. Nakata, and Y. Shimomura, "Synthesis of N,O-acylated chitosan and its sorptivity," Chitin and Chitosan Research, vol. 7, pp. 212-213, 2001.
[176] K. Inoue, K. Yoshizuka, K. Ohto, and H. Nakagawa, "Solvent extraction of some metal ions with lipophilic chitosan chemically modified with functional groups of dithiocarbamate," Chemistry Letters, no. 7, pp. 698-699, 2001.

[177] S. Nishimura, O. Kohgo, K. Kurita, C. Vittavatvong, and H. Kusuhara, "Syntheses of novel chitosan derivatives soluble in organic solvents by regioselective chemical modifications," Chemistry Letters, vol. 1, p. 243, 1990.

[178] R. Yamaguchi, Y. Arai, T. Itoh, and S. Hirano, "Preparation of partially $N$-succinylated chitosans and their cross-linked gels," Carbohydrate Research, vol. 88, no. 1, pp. 172-175, 1981.

[179] K. Kurita, H. Ichikawa, H. Fujisaki, and Y. Iwakura, "Studies on chitin 8. Modification reaction of chitin in highly swollen state with aromatic cyclic carboxylic acid anhydrides," Macromolecules Chemistry, vol. 163, pp. 1161-1169, 1982.

[180] S. Hirano, M. Zhang, B. G. Chung, and S. K. Kim, "Nacylation of chitosan fibre and the $N$-deacetylation of chitin fibre and chitin-cellulose blended fibre at a solid state," Carbohydrate Polymers, vol. 41, no. 2, pp. 175-179, 2000.

[181] R. Jayakumar, M. Prabaharan, R. L. Reis, and J. F. Mano, "Graft copolymerized chitosan-present status and applications," Carbohydrate Polymers, vol. 62, no. 2, pp. 142-158, 2005.

[182] V. K. Mourya and N. N. Inamdar, "Chitosan-modifications and applications: opportunities galore," Reactive and Functional Polymers, vol. 68, no. 6, pp. 1013-1051, 2008.

[183] J. D. Merrifield, Synthesis and characterization of thiol grafted chitosan beads for mercury removal, M.S. thesis, University of Maine, Orono, Me, USA, 2002.

[184] C. Jeon and W. H. Höll, "Chemical modification of chitosan and equilibrium study for mercury ion removal," Water Research, vol. 37, no. 19, pp. 4770-4780, 2003.

[185] O. A.C. Monteiro and C. Airoldi, "Some studies of crosslinking chitosan-glutaraldehyde interaction in a homogeneous system," International Journal of Biological Macromolecules, vol. 26, no. 2-3, pp. 119-128, 1999.

[186] P. O. Osifo, A. Webster, H. van der Merwe, H. W. J. P. Neomagus, M. A. van der Gun, and D. M. Grant, "The influence of the degree of cross-linking on the adsorption properties of chitosan beads," Bioresource Technology, vol. 99, no. 15 , pp. 7377-7382, 2008.

[187] W. S. W. Ngah and S. Fatinathan, "Adsorption of $\mathrm{Cu}$ (II) ions in aqueous solution using chitosan beads, chitosan-GLA beads and chitosan-alginate beads," Chemical Engineering Journal, vol. 143, no. 1-3, pp. 62-72, 2008.

[188] W. S. Wan Ngah, C. S. Endud, and R. Mayanar, "Removal of copper(II) ions from aqueous solution onto chitosan and cross-linked chitosan beads," Reactive and Functional Polymers, vol. 50, no. 2, pp. 181-190, 2002.

[189] W. S. W. Ngah, S. Ab Ghani, and A. Kamari, "Adsorption behaviour of $\mathrm{Fe}$ (II) and $\mathrm{Fe}$ (III) ions in aqueous solution on chitosan and cross-linked chitosan beads," Bioresource Technology, vol. 96, no. 4, pp. 443-450, 2005.

[190] L. Martinez, F. Agnely, B. Leclerc et al., "Cross-linking of chitosan and chitosan/poly(ethylene oxide) beads: a theoretical treatment," European Journal of Pharmaceutics and Biopharmaceutics, vol. 67, no. 2, pp. 339-348, 2007.

[191] Y. Baba, N. Matsumura, K. Shiomori, and Y. Kawano, "Selective adsorption of mercury (II) on chitosan derivatives from hydrochloric acid," Analytical Sciences, vol. 14, no. 4, pp. 687-690, 1998. 
[192] R. S. Vieira and M. M. Beppu, "Mercury ion recovery using natural and crosslinked chitosan membranes," Adsorption, vol. 11, no. 1, pp. 731-736, 2005.

[193] B. J. Mcafee, W. D. Gould, J. C. Nadeau, and A. C. A. Da Costa, "Biosorption of metal ions using chitosan, chitin, and biomass of Rhizopus oryzae," Separation Science and Technology, vol. 36, no. 14, pp. 3207-3222, 2001.

[194] B. Martel, M. Devassine, G. Crini, M. Weltrowski, M. Bourdonneau, and M. Morcellet, "Preparation and sorption properties of a $\beta$-cyclodextrin-linked chitosan derivative," Journal of Polymer Science A, vol. 39, no. 1, pp. 169-176, 2001.

[195] K. Sreenivasan, "Synthesis and preliminary studies on a $\beta$ cyclodextrin-coupled chitosan as a novel adsorbent matrix," Journal of Applied Polymer Science, vol. 69, no. 6, pp. 10511055, 1998.

[196] T. Tojima, H. Katsura, S. M. Han et al., "Preparation of an $\alpha$-cyclodextrin-linked chitosan derivative via reductive amination strategy," Journal of Polymer Science A, vol. 36, no. 11, pp. 1965-1968, 1998.

[197] G. Crini, "Recent developments in polysaccharide-based materials used as adsorbents in wastewater treatment," Progress in Polymer Science, vol. 30, no. 1, pp. 38-70, 2005.

[198] Z. Li, X. P. Zhuang, X. F. Liu, Y. L. Guan, and K. D. Yao, "Study on antibacterial $O$-carboxymethylated chitosan/cellulose blend film from $\mathrm{LiCl} / \mathrm{N}, \mathrm{N}$-dimethylacetamide solution," Polymer, vol. 43, no. 4, pp. 1541-1547, 2002.

[199] N. Vallapa, O. Wiarachai, N. Thongchul et al., "Enhancing antibacterial activity of chitosan surface by heterogeneous quaternization," Carbohydrate Polymers, vol. 83, no. 2, pp. 868-875, 2011.

[200] A. Domard, M. Rinaudo, and C. Terrassin, "New method for the quaternization of chitosan," International Journal of Biological Macromolecules, vol. 8, no. 2, pp. 105-107, 1986.

[201] A. Domard, C. Gey, M. Rinaudo, and C. Terrassin, ${ }^{" 13} \mathrm{C}$ and ${ }^{1} \mathrm{H}$ NMR spectroscopy of chitosan and $N$-trimethyl chloride derivatives," International Journal of Biological Macromolecules, vol. 9, no. 4, pp. 233-237, 1987.

[202] C. H. Kim, J. W. Choi, H. J. Chun, and K. S. Choi, "Synthesis of chitosan derivatives with quaternary ammonium salt and their antibacterial activity," Polymer Bulletin, vol. 38, no. 4, pp. 387-393, 1997.

[203] E. A. Stepnova, V. E. Tikhonov, T. A. Babushkina et al., "New approach to the quaternization of chitosan and its amphiphilic derivatives," European Polymer Journal, vol. 43, no. 6, pp. 2414-2421, 2007.

[204] A. M. Naggi, G. Torri, T. Compagnoni, and B. Casu, "Synthesis and physico-chemical properties of a polyampholyte chitosan 6-sulfate," in Chitin in Nature and Technology, R. A. A. Muzzarelli, C. Jeuniaux, and G. W. Gooday, Eds., pp. 371407, Plenum, New York, NY, USA, 1986.

[205] M. Terbojevich, C. Carraro, and A. Cosani, "Solution studies of chitosan 6-O-sulfate," Die Makromolekulare Chemie, vol. 190, pp. 2847-2855, 1989.

[206] K. R. Holme and A. S. Perlin, "Chitosan N-sulfate. A watersoluble polyelectrolyte," Carbohydrate Research, vol. 302, no. 1-2, pp. 7-12, 1997.

[207] A. Heras, N. M. Rodríguez, V. M. Ramos, and E. Agulló, "Nmethylene phosphonic chitosan: a novel soluble derivative," Carbohydrate Polymers, vol. 44, no. 1, pp. 1-8, 2000.

[208] V. M. Ramos, N. M. Rodríguez, M. F. Díaz, M. S. Rodríguez, A. Heras, and E. Agulló, " $N$-methylene phosphonic chitosan. Effect of preparation methods on its properties," Carbohydrate Polymers, vol. 52, no. 1, pp. 39-46, 2003.
[209] K. Kurita, S. Inoue, and S. I. Nishimura, "Preparation of soluble chitin derivatives as reactive precursors for controlled modifications. Tosyl- and iodo-chitins," Journal of Polymer Science A, vol. 29, no. 6, pp. 937-939, 1991.

[210] K. Kurita, Y. Koyama, S. Inoue, and S. I. Nishimura, "((Diethylamino)ethyl)chitins: preparation and properties of novel animated chitin derivatives," Macromolecules, vol. 23, no. 11, pp. 2865-2869, 1990.

[211] R. A. A. Muzzarelli, F. Tanfani, M. Emanuelli, and S. Mariotti, "N-(carboxymethylidene)chitosans and $N$ (carboxymethyl)chitosans: novel chelating polyampholytes obtained from chitosan glyoxylate," Carbohydrate Research, vol. 107, no. 2, pp. 199-214, 1982.

[212] G. K. Moore and G. A. F. Roberts, "Reactions of chitosan: 4. Preparation of organosoluble derivatives of chitosan," International Journal of Biological Macromolecules, vol. 4, no. 4, pp. 246-249, 1982.

[213] P. Albersheim and A. G. Darvill, "Oligosaccharins," Scientific American, vol. 253, pp. 58-64, 1985.

[214] N. Benhamou and P. J. Lafontaine, "Ultrastructural and cytochemical characterization of elicitor-induced structural responses in tomato root tissues infected by Fusarium oxysporum f.Sp. radicis-lycopersici," Planta, vol. 197, no. 1, pp. 89-102, 1994.

[215] A. El Ghaouth, J. Arul, A. Asselin, and N. Benhamou, "Antifungal activity of chitosan on post-harvest pathogens: induction of morphological and cytological alterations in Rhizopus stolonifer," Mycological Research, vol. 96, pp. 769779, 1992.

[216] A. El Ghaouth, R. Pannampalam, F. Castaigne, and J. Arul, "Chitosan coating to extend the storage life of tomatoes," Hortscience, vol. 27, pp. 1016-1018, 1992.

[217] E. A. Quintana-Obregón, M. Plascencia-Jatomea, R. I. Sánchez-Mariñez et al., "Effects of middle-viscosity chitosan on Ramularia cercosporelloides," Crop Protection, vol. 30, no. 1, pp. 88-90, 2011.

[218] W. Xia, P. Liu, J. Zhang, and J. Chen, "Biological activities of chitosan and chitooligosaccharides," Food Hydrocolloids, vol. 25, pp. 170-179, 2011.

[219] E.-R. Kenawy, F. I. Abdel-Hay, A. A. El-Magd, and Y. Mahmoud, "Biologically active polymers: modification and anti-microbial activity of chitosan derivatives," Journal of Bioactive and Compatible Polymers, vol. 22, pp. 525-538, 2007.

[220] M. E. I. Badawy and E. I. Rabea, "Potential of the biopolymer chitosan with different molecular weights to control postharvest gray mold of tomato fruit," Postharvest Biology and Technology, vol. 51, no. 1, pp. 110-117, 2009.

[221] Z. Guo, R. Chen, R. Xing et al., "Novel derivatives of chitosan and their antifungal activities in vitro," Carbohydrate Research, vol. 341, no. 3, pp. 351-354, 2006.

[222] Z. Guo, R. Xing, S. Liu et al., "Antifungal properties of Schiff bases of chitosan, $\mathrm{N}$-substituted chitosan and quaternized chitosan," Carbohydrate Research, vol. 342, no. 10, pp. 13291332, 2007.

[223] D. F. Kendra and L. A. Hadwiger, "Characterization of the smallest chitosan oligomer that is maximally antifungal to Fusarium solani and elicits pisatin formation in Pisum sativum," Experimental Mycology, vol. 8, no. 3, pp. 276-281, 1984.

[224] S. Sekiguchi, Y. Miura, H. Kaneko et al., "Molecular weight dependency of antimicrobial activity by chitosan oligomers," 
in Food Hydrocolloids: Structures, Properties, and Functions, K. Nishinari and E. Doi, Eds., pp. 71-76, Plenum, New York, NY, USA, 1994.

[225] V. E. Tikhonov, E. A. Stepnova, V. G. Babak et al., "Bactericidal and antifungal activities of a low molecular weight chitosan and its $N$-/2(3)-(dodec-2-enyl)succinoyl/derivatives," Carbohydrate Polymers, vol. 64, no. 1, pp. 66-72, 2006.

[226] G. J. Tsai and W. H. Su, "Antibacterial activity of shrimp chitosan against Escherichia coli," Journal of Food Protection, vol. 62, no. 3, pp. 239-243, 1999.

[227] Y. Uchida, M. Izume, and A. Ohtakara, "Preparation of chitosan oligomers with purified chitosanase and its application," in Chitin and Chitosan: Sources, Chemistry, Biochemistry, Physical Properties and Applications, G. SkjåkBræk et al., Ed., pp. 373-382, Elsevier, London, UK, 1989.

[228] M. Aider, "Chitosan application for active bio-based films production and potential in the food industry: review," LWT-Food Science and Technology, vol. 43, no. 6, pp. 837$842,2010$.

[229] S. Bautista-Baños, A. N. Hernández-Lauzardo, M. G. Velázquez-Del Valle et al., "Chitosan as a potential natural compound to control pre and postharvest diseases of horticultural commodities," Crop Protection, vol. 25, no. 2, pp. 108-118, 2006.

[230] P. K. Dutta, S. Tripathi, G. K. Mehrotra, and J. Dutta, "Perspectives for chitosan based antimicrobial films in food applications," Food Chemistry, vol. 114, no. 4, pp. 1173-1182, 2009.

[231] M. Kong, X. G. Chen, K. Xing, and H. J. Park, “Antimicrobial properties of chitosan and mode of action: a state of the art review," International Journal of Food Microbiology, vol. 144, no. 1, pp. 51-63, 2010.

[232] S. Roller and N. Covill, "The antifungal properties of chitosan in laboratory media and apple juice," International Journal of Food Microbiology, vol. 47, no. 1-2, pp. 67-77, 1999.

[233] V. M. Chau, H. D. Pham, L. H. Dang, D. H. Trinh, and T. H. Hoang, "Use of chitosan in agriculture and food preservation. I. Chitosan as a fresh fruit pres," Vietnam Journal of Chemistry, vol. 34, pp. 29-33, 1996.

[234] C. S. Chen, W. Y. Liau, and G. J. Tsai, "Antibacterial effects of $N$-sulfonated and $N$-sulfobenzoyl chitosan and application to oyster preservation," Journal of Food Protection, vol. 61, no. 9, pp. 1124-1128, 1998.

[235] A. El Ghaouth, J. Arul, J. Grenier, and A. Asselin, “Antifungal activity of chitosan on two postharvest pathogens of strawberry fruits," Phytopathology, vol. 82, pp. 398-402, 1992.

[236] A. N. Hernández-Lauzardo, S. Bautista-Baños, M. G. Velázquez-del Valle, M. G. Méndez-Montealvo, M. M. Sánchez-Rivera, and L. A. Bello-Pérez, "Antifungal effects of chitosan with different molecular weights on in vitro development of Rhizopus stolonifer (Ehrenb.:Fr.) Vuill," Carbohydrate Polymers, vol. 73, no. 4, pp. 541-547, 2008.

[237] K. Ito, E. Tsuburaya, and K. Kawamura, "Acetic acid and chitosan hydrolyzates as microbicides in rice paddies," Japanese Kokai Tokkyo Koho, JP 06227930, 1994.

[238] J. Knowles and S. Roller, "Efficacy of chitosan, carvacrol, and a hydrogen peroxide-based biocide against foodborne microorganisms in suspension and adhered to stainless steel," Journal of Food Protection, vol. 64, no. 10, pp. 1542-1548, 2001.
[239] A. M. Papineau, D. G. Hoover, D. Knorr, and D. F. Farkas, "Antimicrobial effect of water-soluble chitosans with high hydrostatic pressure," Food Biotechnology, vol. 5, no. 1, pp. 45-57, 1991.

[240] J. Rhoades and S. Roller, "Antimicrobial actions of degraded and native chitosan against spoilage organisms in laboratory media and foods," Applied and Environmental Microbiology, vol. 66, no. 1, pp. 80-86, 2000.

[241] H. J. Seo, K. Mitsuhashi, and H. Tanibe, "Antibacterial and antifungal fiber blended by chitosan," in Advances in Chitin and Chitosan, C. J. Brine, P. A. Sandford, and J. P. Zikakis, Eds., pp. 34-40, Elsevier, New York, NY, USA, 1992.

[242] A. K. Sinha, A. K. Chowdhury, and A. R. Das, "Chitosan induces resistance in crop plants against their fungal pathogens," Industrial Phytopathology, vol. 46, pp. 411-414, 1993.

[243] N. R. Sudarshan, D. G. Hoover, and D. Knorr, "Antibacterial action of chitosan," Food Biotechnology, vol. 6, no. 3, pp. 257272, 1992.

[244] G. H. Wang, "Inhibition and inactivation of five species of foodborne pathogens by chitosan," Journal of Food Protection, vol. 55, pp. 916-919, 1992.

[245] X. Liu, Y. G. Du, and X. F. Bai, "Relieving effects of oligoglucosamine on the inhibition induced by deoxynivalenol in wheat embryo cells," Acta Botanica Sinica, vol. 43, pp. 370374, 2001.

[246] C. R. Allan and L. A. Hadwiger, "The fungicidal effect of chitosan on fungi of varying cell wall composition," Experimental Mycology, vol. 3, no. 3, pp. 285-287, 1979.

[247] P. J. Chien and C. C. Chou, "Antifungal activity of chitosan and its application to control post-harvest quality and fungal rotting of Tankan citrus fruit (Citrus tankan Hayata)," Journal of the Science of Food and Agriculture, vol. 86, no. 12, pp. 1964-1969, 2006.

[248] N. Benhamou, P. J. Lafontaine, and M. Nicole, "Induction of systemic resistance to fusarium crown and root rot in tomato plants by seed treatment with chitosan," Phytopathology, vol. 84, no. 12, pp. 1432-1444, 1994.

[249] A. El Ghaouth, J. Arul, C. Wilson, and N. Benhamou, "Ultrastructural and cytochemical aspects of the effect of chitosan on decay of bell pepper fruit," Physiological and Molecular Plant Pathology, vol. 44, no. 6, pp. 417-432, 1994.

[250] M. E. I. Badawy, S. M. Ahmed, and E. I. Rabea, "Bactericidal and fungicidal activities of different molecular weight chitosan samples," Journal of Pest Control and Environmental Sciences, vol. 14, pp. 19-34, 2006.

[251] L. H. Cheah and B. B. C. Page, "Trichoderma spp. for potential biocontrol of clubroot of vegetable brassicas," in Proceedings of 50th New Zealand Plant Protection Conference, pp. 150-153, 1997.

[252] H. E. Wade and J. A. Lamondia, "Chitosan inhibits Rhizoctonia fragariae but not strawberry black root rot," Advanced Strawberry Research, vol. 13, pp. 26-31, 1994.

[253] S. Bautista-Baños, M. Hernández-López, E. Bosquez-Molina, and C. L. Wilson, "Effects of chitosan and plant extracts on growth of Colletotrichum gloeosporioides, anthracnose levels and quality of papaya fruit," Crop Protection, vol. 22, no. 9, pp. 1087-1092, 2003.

[254] S. Bautista-Baños, M. Hernández-López, and E. BosquezMolina, "Growth inhibition of selected fungi by chitosan and plant extracts," Mexican Journal of Phytopathology, vol. 22, pp. 178-186, 2004. 
[255] M. E. I. Badawy, "Effect of depolymerization degree of the natural biopolymer chitosan on some plant pathogenic bacteria and fungi," Journal of Pest Control and Environmental Sciences, vol. 15, pp. 69-85, 2007.

[256] SE. K. Kim and N. Rajapakse, "Enzymatic production and biological activities of chitosan oligosaccharides (COS): a review," Carbohydrate Polymers, vol. 62, no. 4, pp. 357-368, 2005.

[257] W. F. Zhang, D. F. Li, W. Q. Lu, and G. F. Yi, "Effects of isomalto-oligosaccharides on broiler performance and intestinal microflora," Poultry Science, vol. 82, no. 4, pp. 657663, 2003.

[258] J. Xu, X. Zhao, X. Han, and Y. Du, "Antifungal activity of oligochitosan against Phytophthora capsici and other plant pathogenic fungi in vitro," Pesticide Biochemistry and Physiology, vol. 87, no. 3, pp. 220-228, 2007.

[259] S. Hirano and N. Nagao, "Effects of chitosan, pectic acid, lysozyme, and chitinase on the growth of several phytopathogens," Agriculture and Biological Chemistry, vol. 53, pp. 3065-3066, 1989.

[260] S. Bautista-Baños, M. Hernández-López, A. N. HernándezLauzardo, J. L. Trejo-Espino, M. Bautista-Cerón, and G. E. Melo-Giorgana, "Effect of chitosan on in vitro development and morphology of two isolates of Colletotrichum gloeosporioides (Penz.) Penz. and Sacc," Mexican Journal of Phytopathology, vol. 23, pp. 62-67, 2005.

[261] X. Meng, L. Yang, J. F. Kennedy, and S. Tian, "Effects of chitosan and oligochitosan on growth of two fungal pathogens and physiological properties in pear fruit," Carbohydrate Polymers, vol. 81, no. 1, pp. 70-75, 2010.

[262] A. N. Hernández-Lauzardo, M. Hernández-Martínez, M. G. Velázquez-del Valle, and G. E. Melo-Giorgana, "Actividad antifúngica del quitosano en el control de Rhizopus stolonifer (Ehrenb.: Fr) Vuill. y Mucor spp," Revista Mexicana de Fitopatología, vol. 25, pp. 109-113, 2007.

[263] C. Chittenden and T. Singh, "In vitro evaluation of combination of Trichoderma harzianum and chitosan for the control of sapstain fungi," Biological Control, vol. 50, no. 3, pp. 262266, 2009.

[264] Z. M. Kochkina, H. Pospieszny, and S. N. Chrkov, "Inhibition by chitosan of productive infection of the T-series bacteriophages in an Escherichia coli culture," Microbiology, vol. 64, pp. 173-176, 1995.

[265] G. Ma, D. Yang, Y. Zhou, M. Xiao, J. F. Kennedy, and J. $\mathrm{Nie}$, "Preparation and characterization of water-soluble $\mathrm{N}$ alkylated chitosan," Carbohydrate Polymers, vol. 74, no. 1, pp. 121-126, 2008.

[266] M. Másson, J. Holappa, M. Hjálmarsdóttir, O. V. Rúnarsson, T. Nevalainen, and T. Järvinen, "Antimicrobial activity of piperazine derivatives of chitosan," Carbohydrate Polymers, vol. 74, no. 3, pp. 566-571, 2008.

[267] R. A. A. Muzzarelli, "Carboxymethylated chitins and chitosans," Carbohydrate Polymers, vol. 8, no. 1, pp. 1-21, 1988.

[268] F. Seyfarth, S. Schliemann, P. Elsner, and U.-C. Hipler, "Antifungal effect of high- and low-molecular-weight chitosan hydrochloride, carboxymethyl chitosan, chitosan oligosaccharide and $\mathrm{N}$-acetyl-d-glucosamine against Candida albicans, Candida krusei and Candida glabrata," International Journal of Pharmaceutics, vol. 353, no. 1-2, pp. 139-148, 2008.

[269] Z. Zhong, R. Xing, S. Liu et al., "Synthesis of acyl thiourea derivatives of chitosan and their antimicrobial activities in vitro," Carbohydrate Research, vol. 343, no. 3, pp. 566-570, 2008.
[270] J. Holappa, T. Nevalainen, R. Safin et al., "Novel watersoluble quaternary piperazine derivatives of chitosan: synthesis and characterization," Macromolecular Bioscience, vol. 6, no. 2, pp. 139-144, 2006.

[271] R. F. Borch, M. D. Bernstein, and H. D. Durst, "The cyanohydridoborate anion as a selective reducing agent," Journal of the American Chemical Society, vol. 93, no. 12, pp. 2897-2904, 1971.

[272] R. A. A. Muzzarelli, C. Muzzarelli, R. Tarsi, M. Miliani, F. Gabbanelli, and M. Cartolari, "Fungistatic activity of modified chitosans against Saprolegnia parasitica," Biomacromolecules, vol. 2, no. 1, pp. 165-169, 2001.

[273] L. A. Hadwiger and J. M. Beckman, "Chitosan as a component of Pea-Fusarium solani interactions," Plant Physiology, vol. 66, pp. 205-211, 1980.

[274] R. G. Cuero, G. Osuji, and A. Washington, "Ncarboxymethylchitosan inhibition of aflatoxin production: role of zinc," Biotechnology Letters, vol. 13, no. 6, pp. 441-444, 1991.

[275] R. G. Cuero, E. Duffus, G. Osuji, and R. Pettit, "Aflatoxin control in preharvest maize: effects of chitosan and two microbial agents," Journal of Agricultural Science, vol. 117, no. 2, pp. 165-169, 1991.

[276] P. Stossel and J. L. Leuba, "Effect of chitosan, chitin and some aminosugars on growth of various soilborne phytopathogenic fungi," Journal of Phytopathology, vol. 111, pp. 82-90, 1984.

[277] P. Laflamme, N. Benhamou, G. Bussières, and M. Dessureault, "Differential effect of chitosan on root rot fungal pathogens in forest nurseries," Canadian Journal of Botany, vol. 77, no. 10, pp. 1460-1468, 1999.

[278] A. J. El Ghaouth and A. Asselin, "Potential uses of chitosan in postharvest preservation of fruits and vegetables," in Advances in Chitin and Chitosan, C. J. Brine, P. A. Sandford, and J. P. Zikakis, Eds., p. 440, Elsevier, Amsterdam, The Netherlands, 1992.

[279] A. A. Bell, J. C. Hubbard, L. Liu, R. Michael Davis, and K. V. Subbarao, "Effects of chitin and chitosan on the incidence and severity of Fusarium yellows of celery," Plant Disease, vol. 82, no. 3, pp. 322-328, 1998.

[280] F. Daayf, M. El Bellaj, M. El Hassni, F. J'Aiti, and I. El Hadrami, "Elicitation of soluble phenolics in date palm (Phoenix dactylifera) callus by Fusarium oxysporum f. sp. albedinis culture medium," Environmental and Experimental Botany, vol. 49, no. 1, pp. 41-47, 2003.

[281] M. El Hassni, A. El Hadrami, F. Daayf, E. A. Barka, and I. El Hadrami, "Chitosan, antifungal product against Fusarium oxysporum f. sp. albedinis and elicitor of defence reactions in date palm roots," Phytopathologia Mediterranea, vol. 43, no. 2, pp. 195-204, 2004.

[282] J. G. Murphy, S. M. Rafferty, and A. C. Cassells, "Stimulation of wild strawberry (Fragaria vesca) arbuscular mycorrhizas by addition of shellfish waste to the growth substrate: interaction between mycorrhization, substrate amendment and susceptibility to red core (Phytophthora fragariae)," Applied Soil Ecology, vol. 15, no. 2, pp. 153-158, 2000.

[283] K. K. Pal and B. McSpadden Gardener, "Biological control of plant pathogens," The Plant Health Instructor, vol. 2, pp. 1117-1142, 2006.

[284] A. K. Uppal, A. El Hadrami, L. R. Adam, M. Tenuta, and F. Daayf, "Biological control of potato Verticillium wilt under controlled and field conditions using selected bacterial antagonists and plant extracts," Biological Control, vol. 44, no. 1, pp. 90-100, 2008. 
[285] G. K. Agrawal, R. Rakwal, S. Tamogami, M. Yonekura, A. Kubo, and H. Saji, "Chitosan activates defense/stress response(s) in the leaves of Oryza sativa seedlings," Plant Physiology and Biochemistry, vol. 40, no. 12, pp. 1061-1069, 2002.

[286] W. Lin, X. Hu, W. Zhang, W. John Rogers, and W. Cai, "Hydrogen peroxide mediates defence responses induced by chitosans of different molecular weights in rice," Journal of Plant Physiology, vol. 162, no. 8, pp. 937-944, 2005.

[287] S. Boonlertnirun, C. Boonraung, and R. Suvanasara, "Application of chitosan in Rice production," Journal of Metals, Materials and Minerals, vol. 18, pp. 47-52, 2008.

[288] D. Zeng and Y. Shi, "Preparation and application of a novel environmentally friendly organic seed coating for rice," Journal of the Science of Food and Agriculture, vol. 89, no. 13, pp. 2181-2185, 2009.

[289] G. F. Burkhanova, L. G. Yarullina, and I. V. Maksimov, "The control of wheat defense responses during infection with Bipolaris sorokiniana by chitooligosaccharides," Russian Journal of Plant Physiology, vol. 54, no. 1, pp. 104-110, 2007.

[290] R. M. Khairullin, L. G. Yarullina, N. B. Troshina, and I. E. Akhmetova, "Chitooligosaccharide-induced activation of $O$-phenylenediamine oxidation by wheat seedlings in the presence of oxalic acid," Biochemistry, vol. 66, no. 3, pp. 286289, 2001.

[291] X. F. Liu, Y. L. Guan, D. Z. Yang, Z. Li, and K. D. Yao, "Antibacterial action of chitosan and carboxymethylated chitosan," Journal of Applied Polymer Science, vol. 79, no. 7, pp. 1324-1335, 2001.

[292] M. V. B. Reddy, J. Arul, P. Angers, and L. Couture, "Chitosan treatment of wheat seeds induces resistance to Fusarium graminearum and improves seed quality," Journal of Agricultural and Food Chemistry, vol. 47, no. 3, pp. 1208-1216, 1999.

[293] A. B. Falcón, J. C. Cabrera, D. Costales et al., "The effect of size and acetylation degree of chitosan derivatives on tobacco plant protection against Phytophthora parasitica nicotianae," World Journal of Microbiology and Biotechnology, vol. 24, no. 1, pp. 103-112, 2008.

[294] H. Yin, X. Bai, and Y. Du, "The primary study of oligochitosan inducing resistance to S. sclerotiorum on B. napus," Journal of Biotechnology, vol. 136S, pp. 600-601, 2008.

[295] Z. G. Lu, X. G. Qian, and Y. Peng, "An applied study of chitoligmer rapeseed coating agent," Seed, vol. 4, pp. 38-40, 2003.

[296] S. N. Chirkov, A. V. Il'ina, N. A. Surgucheva et al., "Effect of chitosan on systemic viral infection and some defense responses in potato plants," Russian Journal of Plant Physiology, vol. 48, no. 6, pp. 774-779, 2001.

[297] S. N. Chirkov, "The antiviral activity of chitosan," Applied Biochemistry and Microbiology, vol. 38, no. 1, pp. 1-8, 2002.

[298] F. Faoro, S. Sant, M. Iriti, and A. Appiano, "Chitosan-elicited resitance to plant viruses: a histochemical and cytochemical study," in Chitin Enzymology, R. A. A. Muzzarelli, Ed., pp. 5762, Atec, Grottammare, Italy, 2001.

[299] W. Guang Liu and K. De Yao, "Chitosan and its derivativesa promising non-viral vector for gene transfection," Journal of Controlled Release, vol. 83, no. 1, pp. 1-11, 2002.

[300] H. Pospieszny, "Antiviroid activity of chitosan," Crop Protection, vol. 16, no. 2, pp. 105-106, 1997.

[301] H. Pospieszny, S. Chirkov, and J. Atabekov, "Induction of antiviral resistance in plants by chitosan," Plant Science, vol. 79, no. 1, pp. 63-68, 1991.
[302] N. Ben-Shalom, R. Ardi, R. Pinto, C. Aki, and E. Fallik, "Controlling gray mould caused by Botrytis cinerea in cucumber plants by means of chitosan," Crop Protection, vol. 22, no. 2, pp. 285-290, 2003.

[303] J. Postma and M. J. E. I. M. Willemsen-De Klein, "Biological control of Pythium aphanidermatum in cucumber with combined applications of bacterial antagonists with chitosan," IOBC/wprs Bulletin, vol. 27, pp. 101-104, 2004.

[304] J. Postma, L. H. Stevens, G. L. Wiegers, E. Davelaar, and E. H. Nijhuis, "Biological control of Pythium aphanidermatum in cucumber with a combined application of Lysobacter enzymogenes strain 3.1T8 and chitosan," Biological Control, vol. 48, no. 3, pp. 301-309, 2009.

[305] N. I. Vasyukova, S. V. Zinoveva, L. I. Ilinskaya et al., "Modulation of plant resistance to diseases by water-soluble chitosan," Applied Biochemistry and Microbiology, vol. 37, no. 1, pp. 103-109, 2001.

[306] N. Benhamou, J. W. Kloepper, and S. Tuzun, "Induction of resistance against Fusarium wilt of tomato by combination of chitosan with an endophytic bacterial strain: ultrastructure and cytochemistry of the host response," Planta, vol. 204, no. 2, pp. 153-168, 1998.

[307] A. Aziz, A. Heyraud, and B. Lambert, "Oligogalacturonide signal transduction, induction of defense-related responses and protection of grapevine against Botrytis cinerea," Planta, vol. 218, no. 5, pp. 767-774, 2004.

[308] Z. Muñoz, A. Moret, and S. Garcés, "Assessment of chitosan for inhibition of Colletotrichum sp. on tomatoes and grapes," Crop Protection, vol. 28, no. 1, pp. 36-40, 2009.

[309] P. Trotel-Aziz, M. Couderchet, G. Vernet, and A. Aziz, "Chitosan stimulates defense reactions in grapevine leaves and inhibits development of Botrytis cinerea," European Journal of Plant Pathology, vol. 114, no. 4, pp. 405-413, 2006.

[310] Y.-J. Guan, J. Hu, X.-J. Wang, and C.-X. Shao, "Seed priming with chitosan improves maize germination and seedling growth in relation to physiological changes under low temperature stress," Journal of Zhejiang University Science $B$, vol. 10, no. 6, pp. 427-433, 2009.

[311] C.-X. Shao, J. Hu, W.-J. Song, and W.-M. Hu, "Effects of seed priming with chitosan solutions of different acidity on seed germination and physiological characteristics of maize seedling," Journal of the Zhejiang University-Agriculture and Life Science, vol. 31, no. 6, pp. 705-708, 2005.

[312] Y. G. Zhou, Y. D. Yang, Y. G. Qi, Z. M. Zhang, X. J. Wang, and X. J. Hu, "Effects of chitosan on some physiological activity in germinating seed of peanut," Journal of Peanut Science, vol. 31, pp. 22-25, 2002.

[313] S. L. Ruan and Q. Z. Xue, "Effects of chitosan coating on seed germination and salt-tolerance of seedlings in hybrid rice (Oryza sativa L.)," Acta Agronomica Sinica, vol. 28, pp. 803-808, 2002.

[314] F. Faoro, D. Maffi, D. Cantu, and M. Iriti, "Chemical-induced resistance against powdery mildew in barley: the effects of chitosan and benzothiadiazole," BioControl, vol. 53, no. 2, pp. 387-401, 2008.

[315] G. Manjunatha, K. S. Roopa, G. N. Prashanth, and H. Shekar Shetty, "Chitosan enhances disease resistance in pearl millet against downy mildew caused by Sclerospora graminicola and defence-related enzyme activation," Pest Management Science, vol. 64, no. 12, pp. 1250-1257, 2008.

[316] C. Molloy, L. H. Cheah, and J. P. Koolaard, "Induced resistance against Sclerotinia sclerotiorum in carrots treated with enzymatically hydrolysed chitosan," Postharvest Biology and Technology, vol. 33, no. 1, pp. 61-65, 2004. 
[317] P. Nandeeshkumar, J. Sudisha, K. K. Ramachandra, H. S. Prakash, S. R. Niranjana, and S. H. Shekar, "Chitosan induced resistance to downy mildew in sunflower caused by Plasmopara halstedii," Physiological and Molecular Plant Pathology, vol. 72, no. 4-6, pp. 188-194, 2008.

[318] G. Lizama-Uc, I. A. Estrada-Mota, M. G. Caamal-Chan et al., "Chitosan activates a MAP-kinase pathway and modifies abundance of defense-related transcripts in calli of Cocos nucifera L," Physiological and Molecular Plant Pathology, vol. 70, no. 4-6, pp. 130-141, 2007.

[319] S. I. Park, S. D. Stan, M. A. Daeschel, and Y. Zhao, "Antifungal coatings on fresh strawberries (Fragaria $\mathrm{x}$ ananassa) to control mold growth during cold storage," Journal of Food Science, vol. 70, no. 4, pp. M202-M207, 2005.

[320] A. El-Ghaouth, J. L. Smilanick, and C. L. Wilson, "Enhancement of the performance of Candida saitoana by the addition of glycolchitosan for the control of postharvest decay of apple and citrus fruit," Postharvest Biology and Technology, vol. 19, no. 1, pp. 103-110, 2000.

[321] C. L. Fisk, A. M. Silver, B. C. Strik, and Y. Zhao, "Postharvest quality of hardy kiwifruit (Actinidia arguta 'Ananasnaya') associated with packaging and storage conditions," Postharvest Biology and Technology, vol. 47, no. 3, pp. 338-345, 2008.

[322] L. A. Terry and D. C. Joyce, "Elicitors of induced disease resistance in postharvest horticultural crops: a brief review," Postharvest Biology and Technology, vol. 32, no. 1, pp. 1-13, 2004.

[323] R. A. A. Muzzarelli, C. Jeuniaux, and G. W. Gooday, Eds., Chitin in Nature and Technology, Plenum, New York, NY, USA, 1986.

[324] G. Romanazzi, F. Nigro, A. Ippolito, D. Di Venere, and M. Salerno, "Effects of pre- and postharvest chitosan treatments to control storage grey mould of table grapes," Journal of Food Science, vol. 67, pp. 1862-1867, 2002.

[325] R. K. Bai, M. Y. Huang, and Y. Y. Jiang, "Selective permeabilities of chitosan-acetic acid comlex membrane and chitosan-polymer complex membranes for oxygen and carbondioxide," Polymer Bulletin, vol. 20, pp. 83-88, 1988.

[326] A. El Ghaouth, J. Arul, R. Pannampalam, and M. Boulet, "Chitosan coating effect on storability and quality of fresh strawberries," Journal of Food Science, vol. 56, pp. 1618-1621, 1991.

[327] C. Han, Y. Zhao, S. W. Leonard, and M. G. Traber, "Edible coatings to improve storability and enhance nutritional value of fresh and frozen strawberries (Fragaria $\mathrm{x}$ ananassa) and raspberries (Rubus ideaus)," Postharvest Biology and Technology, vol. 33, no. 1, pp. 67-78, 2004.

[328] P. Hernández-Muñoz, E. Almenar, M. J. Ocio, and R. Gavara, "Effect of calcium dips and chitosan coatings on postharvest life of strawberries (Fragaria $\mathrm{x}$ ananassa)," Postharvest Biology and Technology, vol. 39, no. 3, pp. 247-253, 2006.

[329] M. V. Bhaskara Reddy, K. Belkacemi, R. Corcuff, F. Castaigne, and J. Arul, "Effect of pre-harvest chitosan sprays on postharvest infection by Botrytis cinerea quality of strawberry fruit," Postharvest Biology and Technology, vol. 20, no. 1, pp. 39-51, 2000.

[330] M. Vargas, A. Albors, A. Chiralt, and C. González-Martínez, "Quality of cold-stored strawberries as affected by chitosanoleic acid edible coatings," Postharvest Biology and Technology, vol. 41, no. 2, pp. 164-171, 2006.

[331] H. Li and T. Yu, "Effect of chitosan on incidence of brown rot, quality and physiological attributes of postharvest peach fruit," Journal of the Science of Food and Agriculture, vol. 81, no. 2, pp. 269-274, 2001.
[332] Y. Caro and J. Joas, "Postharvest control of litchi pericarp browning (cv. Kwai Mi) by combined treatments of chitosan and organic acids: II. Effect of the initial water content of pericarp," Postharvest Biology and Technology, vol. 38, no. 2, pp. 137-144, 2005.

[333] Y. Jiang, J. Li, and W. Jiang, "Effects of chitosan coating on shelf life of cold-stored litchi fruit at ambient temperature," LWT_Food Science and Technology, vol. 38, no. 7, pp. 757$761,2005$.

[334] J. Joas, Y. Caro, M. N. Ducamp, and M. Reynes, "Postharvest control of pericarp browning of litchi fruit (Litchi chinensis Sonn cv Kwai Mi) by treatment with chitosan and organic acids. I. Effect of $\mathrm{pH}$ and pericarp dehydration," Postharvest Biology and Technology, vol. 38, no. 2, pp. 128-136, 2005.

[335] D. Zhang and P. C. Quantick, "Effects of chitosan coating on enzymatic browning and decay during postharvest storage of litchi (Litchi chinensis Sonn.) fruit," Postharvest Biology and Technology, vol. 12, no. 2, pp. 195-202, 1997.

[336] H. Dong, L. Cheng, J. Tan, K. Zheng, and Y. Jiang, "Effects of chitosan coating on quality and shelf life of peeled litchi fruit," Journal of Food Engineering, vol. 64, no. 3, pp. 355-358, 2004.

[337] Y. Jiang and Y. Li, "Effects of chitosan coating on postharvest life and quality of longan fruit," Food Chemistry, vol. 73, no. 2, pp. 139-143, 2001.

[338] L. T. Pen and Y. M. Jiang, "Effects of chitosan coating on shelf life and quality of fresh-cut Chinese water chestnut," LWT-Food Science and Technology, vol. 36, no. 3, pp. 359364, 2003.

[339] P. J. Chien, F. Sheu, and H. R. Lin, "Coating citrus (Murcott tangor) fruit with low molecular weight chitosan increases postharvest quality and shelf life," Food Chemistry, vol. 100, no. 3, pp. 1160-1164, 2007.

[340] H. Li and T. Yu, "Effect of chitosan on incidence of brown rot, quality and physiological attributes of postharvest peach fruit," Journal of the Science of Food and Agriculture, vol. 81, no. 2, pp. 269-274, 2001.

[341] T. Diab, C. G. Biliaderis, D. Gerasopoulos, and E. Sfakiotakis, "Physicochemical properties and application of pullulan edible films and coatings in fruit preservation," Journal of the Science of Food and Agriculture, vol. 81, no. 10, pp. 988-1000, 2001.

[342] J. J. Kester and O. R. Fennema, "Edible films and coatings: a review," Food Technology, vol. 60, pp. 47-59, 1986.

[343] C. Han, C. Lederer, M. McDaniel, and Y. Zhao, "Sensory evaluation of fresh strawberries (Fragaria ananassa) coated with chitosan-based edible coatings," Journal of Food Science, vol. 70, no. 3, pp. S172-S178, 2005.

[344] G. Romanazzi, F. Nigro, and A. Ippolito, "Short hypobaric treatments potentiate the effect of chitosan in reducing storage decay of sweet cherries," Postharvest Biology and Technology, vol. 29, no. 1, pp. 73-80, 2003.

[345] J. Liu, S. Tian, X. Meng, and Y. Xu, "Effects of chitosan on control of postharvest diseases and physiological responses of tomato fruit," Postharvest Biology and Technology, vol. 44, no. 3, pp. 300-306, 2007.

[346] X. Meng, B. Li, J. Liu, and S. Tian, "Physiological responses and quality attributes of table grape fruit to chitosan preharvest spray and postharvest coating during storage," Food Chemistry, vol. 106, no. 2, pp. 501-508, 2008.

[347] J. E. Fajardo, T. G. McCollum, R. E. McDonald, and R. T. Mayer, "Differential induction of proteins in orange flavedo 
by biologically based elicitors and challenged by Penicillium digitatum Sacc," Biological Control, vol. 13, no. 3, pp. 143151, 1998.

[348] D. Zhang and P. C. Quantick, "Antifungal effects of chitosan coating on fresh strawberries and raspberries during storage," Journal of Horticultural Science and Biotechnology, vol. 73, no. 6, pp. 763-767, 1998.

[349] T. Chen, "The relationship between specific properties and use of chitosan," in Proceedings of the National Symposium on Nature Marine Product and Nature Biological Mmedicine, pp. 282-284, Beijing, China, 1998.

[350] S. Tokura, K. Ueno, S. Miyazaki, and N. Nishi, "Molecular weight dependent antimicrobial activity by chitosan," Macromolecular Symposia, vol. 120, pp. 1-9, 1997.

[351] D. V. Gerasimenko, I. D. Avdienko, G. E. Bannikova, O. Y. Zueva, and V. P. Varlamov, "Antibacterial effects of water-soluble low-molecular-weight chitosans on different microorganisms," Applied Biochemistry and Microbiology, vol. 40, no. 3, pp. 253-257, 2004.

[352] L. Y. Zheng and J. F. Zhu, "Study on antimicrobial activity of chitosan with different molecular weights," Carbohydrate Polymers, vol. 54, no. 4, pp. 527-530, 2003.

[353] K. W. Kim, R. L. Thomas, C. Lee, and H. J. Park, "Antimicrobial activity of native chitosan, degraded chitosan, and $O$ carboxymethylated chitosan," Journal of Food Protection, vol. 66, no. 8, pp. 1495-1498, 2003.

[354] Y. J. Jeon, P. J. Park, and SE. K. Kim, "Antimicrobial effect of chitooligosaccharides produced by bioreactor," Carbohydrate Polymers, vol. 44, no. 1, pp. 71-76, 2001.

[355] Z. Jia, D. Shen, and W. Xu, "Synthesis and antibacterial activities of quaternary ammonium salt of chitosan," Carbohydrate Research, vol. 333, no. 1, pp. 1-6, 2001.

[356] S. Tokura, Y. Miura, M. Johmen, N. Nishi, and S. I. Nishimura, "Induction of drug specific antibody and the controlled release of drug by 6-O-carboxymethyl-chitin," Journal of Controlled Release, vol. 28, no. 1-3, pp. 235-241, 1994.

[357] T. Tanigawa, Y. Tanaka, H. Sashiwa, H. Saimoto, and Y. Shigemasa, "Various biological effects of chitin derivatives," in Advances in Chitin and Chitosan, C. J. Brine, P. A. Sandford, and J. P. Zikakis, Eds., pp. 206-215, Elsevier, London, UK, 1992.

[358] M. Shimojoh, K. Masaki, K. Kurita, and K. Fukushima, "Bactericidal effects of chitosan from squid pens on oral streptococci," Nippon Nogeikagaku Kaishi, vol. 70, no. 7, pp. 787-792, 1996.

[359] M. Yalpani, F. Johnson, and L. E. Robinson, "Antimicrobial activity of some chitosan derivatives," in Advances in Chitin and Chitosan, C. J. Brine, P. A. Sandford, and J. P. Zikakis, Eds., pp. 543-548, Elsevier, London, UK, 1992.

[360] D. S. Chang, H. R. Cho, H. Y. Goo, and W. K. Choe, "A development of food preservative with the waste of crab processing," Bulletin of the Korean Fisheries Society, vol. 22, pp. 70-78, 1989.

[361] K. Ueno, T. Yamaguchi, N. Sakairi, N. Nishi, and S. Tokura, "Antimicrobial activity by fractionated chitosan oligomers," in Advances in Chitin Science, Vol. II, A. Domard, G. A. F. Roberts, and K. M. Vårum, Eds., pp. 156-161, Jacques André Publisher, Lyon, France, 1997.

[362] J. K. Hwang, H. J. Kim, S. J. Yoon, and Y. R. Pyun, "Bactericidal activity of chitosan on E. coli," in Advances in Chitin Science, Vol. III, R. H. Chen and H. C. Chen, Eds., pp. 340-344, Rita, Taipei, Taiwan, 1998.
[363] M. Morimoto and Y. Shigemasa, "Charaterization and bioactivities of chitin and chitosan regulated by their degree of deacetylation," Kobunshi Ronbunshu, vol. 54, pp. 621-631, 1997.

[364] B. K. Simpson, N. Gagné, I. N. A. Ashie, and E. Noroozi, "Utilization of chitosan for preservation of raw shrimp (Pandalus borealis)," Food Biotechnology, vol. 11, no. 1, pp. 25-44, 1997.

[365] G. Ikinci, S. Şenel, H. Akincibay et al., "Effect of chitosan on a periodontal pathogen Porphyromonas gingivalis," International Journal of Pharmaceutics, vol. 235, no. 1-2, pp. 121$127,2002$.

[366] T. Hongpattarakere and O. Riyaphan, "Effect of deacetylation conditions on antimicrobial activity of chitosans prepared from carapace of black tiger shrimp (Penaeus monodon)," Songklanakarin Journal of Science and Technology, vol. 30, pp. $1-9,2008$.

[367] D. H. Young, H. Köhle, and H. Kauss, "Effect of chitosan on membrane permeability of suspension-cultured Glycine max and Phaseolus vulgaris cells," Plant Physiology, vol. 70, pp. 1449-1454, 1982.

[368] D. H. Young and H. Kauss, "Release of calcium from suspension-cultured Glycine max cells by chitosan, other polycations, and polyamines in relation to effects on membrane permeability," Plant Physiology, vol. 73, pp. 698-702, 1983.

[369] M. Ignatova, K. Starbova, N. Markova, N. Manolova, and I. Rashkov, "Electrospun nano-fibre mats with antibacterial properties from quaternised chitosan and poly(vinyl alcohol)," Carbohydrate Research, vol. 341, no. 12, pp. 2098-2107, 2006.

[370] Y. Xie, X. Liu, and Q. Chen, "Synthesis and characterization of water-soluble chitosan derivate and its antibacterial activity," Carbohydrate Polymers, vol. 69, no. 1, pp. 142-147, 2007.

[371] S. Chen, G. Wu, and H. Zeng, "Preparation of high antimicrobial activity thiourea chitosan-Ag complex," Carbohydrate Polymers, vol. 60, no. 1, pp. 33-38, 2005.

[372] I. M. Helander, E. L. Nurmiaho-Lassila, R. Ahvenainen, J. Rhoades, and S. Roller, "Chitosan disrupts the barrier properties of the outer membrane of Gram-negative bacteria," International Journal of Food Microbiology, vol. 71, no. 2-3, pp. 235-244, 2001.

[373] S. W. Fang, C. F. Li, and D. Y. C. Shin, "Antifungal activity of chitosan and its preservative effect on low-sugar candied kumquat," Journal of Food Protection, vol. 57, p. 136, 1994.

[374] L. A. Hadwiger, "How chitosan, a DNA-comlexing carbohydrate activities genes associated with disease resistance in peas," Journal of Cell Biochemistry, vol. 1, supplement 10C, 1986.

[375] B.-O. Jung, C.-H. Kim, K.-S. Choi, Y. M. Lee, and J.-J. Kim, "Preparation of amphiphilic chitosan and their antimicrobial activities," Journal of Applied Polymer Science, vol. 72, no. 13, pp. 1713-1719, 1999.

[376] H. Liu, Y. Du, X. Wang, and L. Sun, "Chitosan kills bacteria through cell membrane damage," International Journal of Food Microbiology, vol. 95, no. 2, pp. 147-155, 2004.

[377] S. Leuba and P. Stossel, "Chitosan and other polyamines: antifungal activity and interaction with biological membranes," in Chitin in Nature and Technology, R. A. A. Muzzarelli, C. Jeuniaux, and G. W. Gooday, Eds., p. 217, Plenum, New York, NY, USA, 1986.

[378] L. A. Hadwiger, D. F. Kendra, B. W. Fristensky, and W. Wagoner, "Chitosan both activates genes in plants and inhibits RNA synthesis in fungi," in Chitin in Nature and 
Technology, R. A. A. Muzzarelli, C. Jeuniaux, and G. W. Gooday, Eds., pp. 209-214, Plenum, New York, NY, USA, 1986.

[379] H. Dörnenburg and D. Knorr, "Evaluation of elicitor- and high-pressure-induced enzymatic browning utilizing potato (Solanum tuberosum) suspension cultures as a model system for plant tissues," Journal of Agricultural and Food Chemistry, vol. 45, no. 10, pp. 4173-4177, 1997.

[380] M. V. Bhaskara Reddy, J. Arul, E. Ait-Barka, P. Angers, C. Richard, and F. Castaigne, "Effect of chitosan on growth and toxin production by Alternaria alternata f. sp. lycopersici," Biocontrol Science and Technology, vol. 8, no. 1, pp. 33-43, 1998.

[381] M. V. Bhaskara Reddy, P. Angers, F. Castaigne, and J. Arul, "Chitosan effects on blackmold rot and pathogenic factors produced by Alternaria alternata in postharvest tomatoes," Journal of the American Society for Horticultural Science, vol. 125, no. 6, pp. 742-747, 2000.

[382] A. El Ghaouth, J. Arul, C. Wilson, and N. Benhamou, "Biochemical and cytochemical aspects of the interactions of chitosan and Botrytis cinerea in bell pepper fruit," Postharvest Biology and Technology, vol. 12, no. 2, pp. 183-194, 1997.

[383] W. H. Daly, "Biocidal chitosan derivatives," US patent no. 6,306,835, 2001.

[384] F. Li, W. G. Liu, and K. D. Yao, "Preparation of oxidized glucose-crosslinked $N$-alkylated chitosan membrane and in vitro studies of $\mathrm{pH}$-sensitive drug delivery behaviour," Biomaterials, vol. 23, no. 2, pp. 343-347, 2002. 


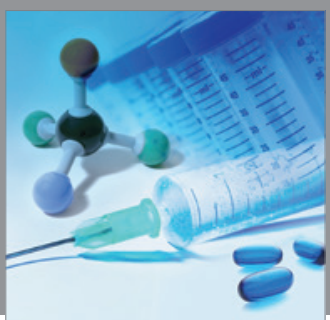

International Journal of

Medicinal Chemistry

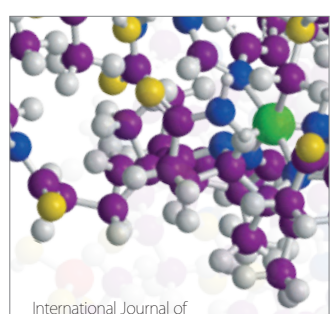

Carbohydrate Chemistry

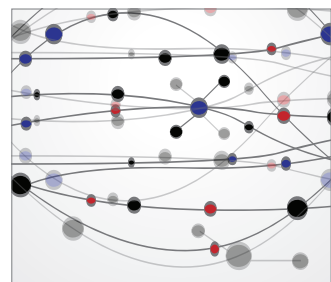

The Scientific World Journal
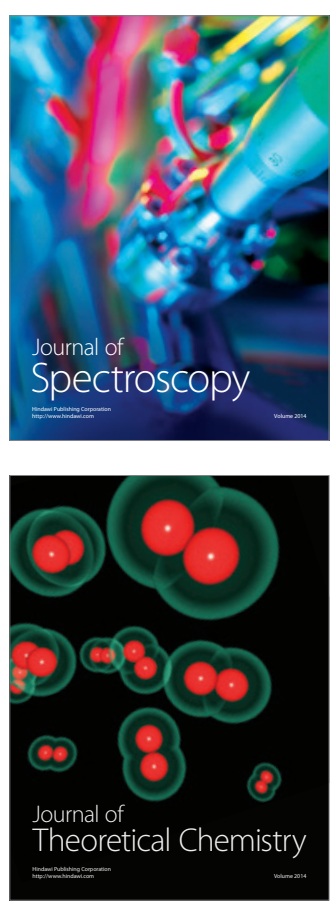
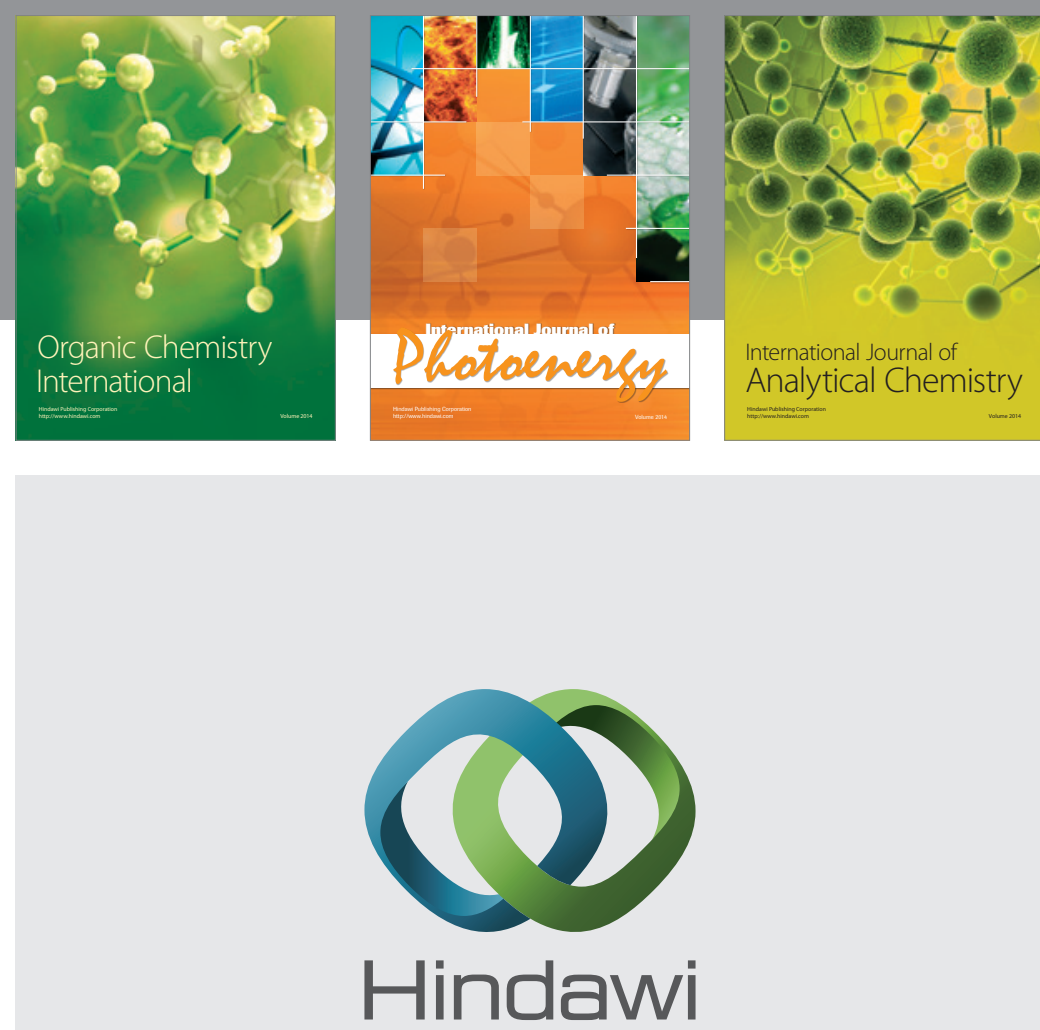

Submit your manuscripts at

http://www.hindawi.com
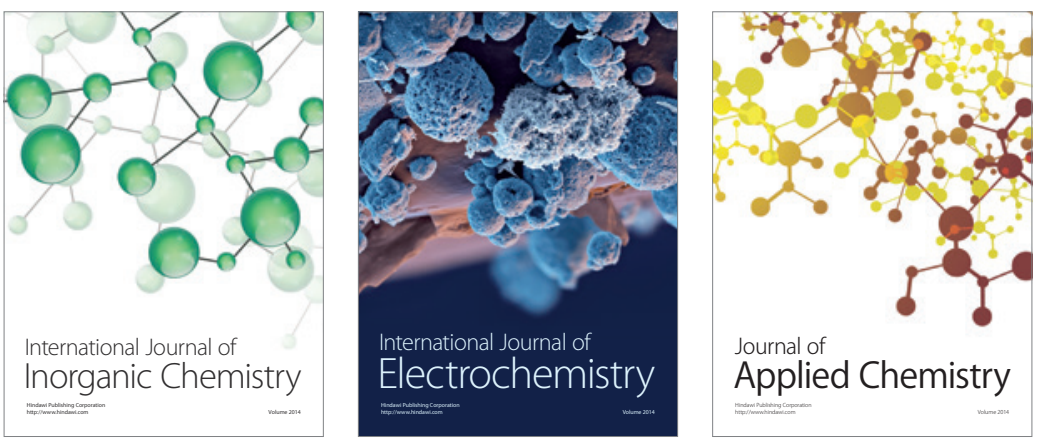

Journal of

Applied Chemistry
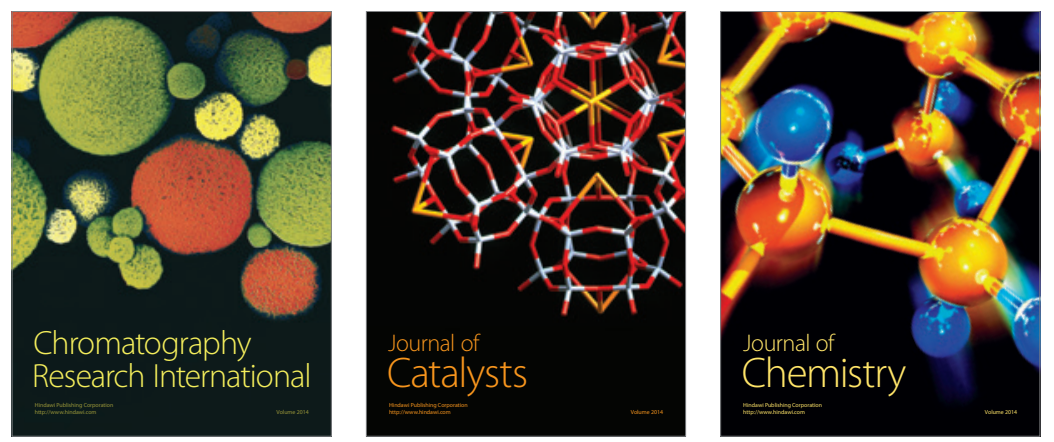
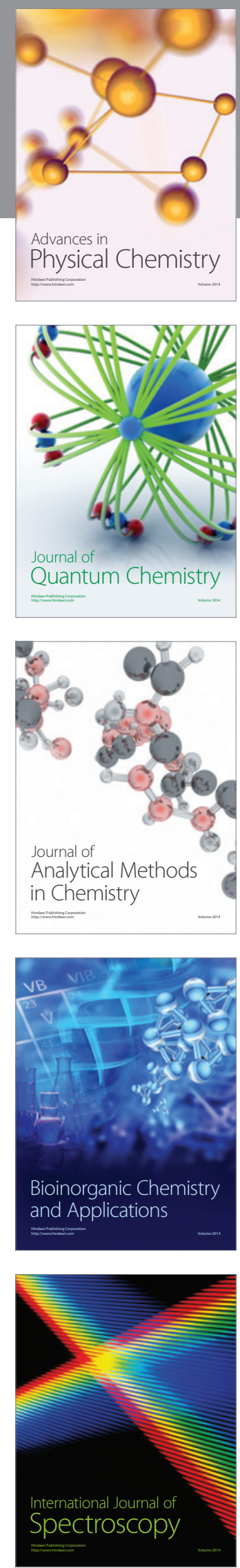